ARTICLE

Received 6 Sep 2016 | Accepted 16 Jan 2017 | Published 24 Feb $2017 \quad$ DOl: 10.1038/ncomms14607 OPEN

\title{
IFN- $\gamma$ is required for cytotoxic T cell-dependent cancer genome immunoediting
}

Kazuyoshi Takeda1,2,3,4, Masafumi Nakayama5,6, Yoshihiro Hayakawa4,7, Yuko Kojima ${ }^{8}$, Hiroaki Ikeda9,10, Naoko Imai ${ }^{9,11}$, Kouetsu Ogasawara ${ }^{6}$, Ko Okumura $2,3,12$, David M. Thomas ${ }^{13}$ \& Mark J. Smyth ${ }^{4,14,15}$

Genetic evolution that occurs during cancer progression enables tumour heterogeneity, thereby fostering tumour adaptation, therapeutic resistance and metastatic potential. Immune responses are known to select (immunoedit) tumour cells displaying immunoevasive properties. Here we address the role of IFN- $\gamma$ in mediating the immunoediting process. We observe that, in several mouse tumour models such as HA-expressing 4T1 mammary carcinoma cells, OVA-expressing EG7 lymphoma cells and CMS5 MCA-induced fibrosarcoma cells naturally expressing mutated extracellular signal-regulated kinase (ERK) antigen, the action of antigen-specific cytotoxic T cell (CTL) in vivo results in the emergence of resistant cancer cell clones only in the presence of IFN- $\gamma$ within the tumour microenvironment. Moreover, we show that exposure of tumours to IFN- $\gamma$-producing antigen-specific CTLs in vivo results in copy-number alterations (CNAs) associated with DNA damage response and modulation of DNA editing/repair gene expression. These results suggest that enhanced genetic instability might be one of the mechanisms by which CTLs and IFN- $\gamma$ immunoedits tumours, altering their immune resistance as a result of genetic evolution.

\footnotetext{
${ }^{1}$ Division of Cell Biology, Biomedical Research Center, Graduate School of Medicine, Juntendo University, Bunkyo-ku, Tokyo 113-8421, Japan. ${ }^{2}$ Department of Biofunctional Micribiota, Graduate School of Medicine, Juntendo University, Bunkyo-ku, Tokyo 113-8421, Japan. ${ }^{3}$ Department of Immunology, Juntendo University School of Medicine, Bunkyo-ku, Tokyo 113-8421, Japan. ${ }^{4}$ Cancer Immunology Program, Peter MacCallum Cancer Centre, St Andrews Place, East Melbourne, 3002 Victoria, Australia. ${ }^{5}$ Frontier Research Institute for Interdisciplinary Sciences, Tohoku University, Sendai 980-8578, Japan. ${ }^{6}$ Department of Immunobiology, Institute of Development, Aging, and Cancer, Tohoku University, Sendai 980-8575, Japan. ${ }^{7}$ Division of Pathogenic Biochemistry, Department of Bioscience, Institute of Natural Medicine, University of Toyama, Sugitani 2630, Toyama 930-0194, Japan. ${ }^{8}$ Laboratory of Morphology and Image Analysis, Biomedical Research Center, Juntendo University Graduate School of Medicine, Tokyo 113-8421, Japan. ${ }^{9}$ Department of Immuno-Gene Therapy, Mie University Graduate School of Medicine, 2-174 Edobashi, Tsu, Mie 514-8507, Japan. ${ }^{10}$ Department of Oncology, Nagasaki University Graduate School of Biomedical Science, 1-12-4 Sakamoto, Nagasaki 852-8523, Japan. ${ }^{11}$ Department of Hematology and Oncology, Icahn School of Medicine at Mount Sinai, 1470 Madison Avenue, New York, New York 10029, USA. ${ }^{12}$ Atopy (Allergy) Research Center, Graduate School of Medicine, Juntendo University, Bunkyo-ku, Tokyo 113-8421, Japan. ${ }^{13}$ Cancer Division, Garvan Institute of Medical Research, Darlinghurst, New South Wales 2010, Australia. ${ }^{14}$ Immunology in Cancer and Infection Laboratory, QIMR Berghofer Medical Research Institute, Herston, 4006 Queensland, Australia. ${ }^{15}$ School of Medicine, University of Queensland, Herston, 4006 Queensland, Australia. Correspondence and requests for materials should be addressed to K.T. (email: ktakeda@juntendo.ac.jp).
} 
mmune responses are known to select (immunoedit) tumour cells displaying immunoevasive properties ${ }^{1-4}$. Both cytotoxic activity and IFN- $\gamma$ production by CTL recognizing tumours are critical for cancer immunoediting, however, whether IFN- $\gamma$ is anti-tumorigenic ${ }^{5-11}$ or pro-tumorigenic ${ }^{12-16}$ remains controversial ${ }^{17-19}$. DNA copy-number alterations (CNAs) are critical pathogenic events that drive tumour development $^{20}$ and are involved in genetic evolution that confers malignant behaviour on cancer cells. Indeed, highly rearranged genomes harbouring many recurrent CNAs have been observed in human and mouse cancers ${ }^{21,22}$. A significantly higher level of CNAs was observed particularly in driver genes of genetically induced mouse non-small-cell lung carcinoma ${ }^{23,24}$. It was recently reported that majority of CNAs are acquired in short punctuated bursts at the earliest stages of tumour evolution ${ }^{25-27}$, possibly under the selective immunoediting pressure of CTL recognizing tumour-specific rejection antigens and acting on tumour cells ${ }^{3}$. Tumours derived from immunodeficient mice often express endogenous tumour-specific rejection antigens and these, or exogenous antigens genetically engineered into tumour cells, can be immunoedited during tumour development ${ }^{3,4}$. To address the mechanism by which IFN- $\gamma$ contributes to cancer immunoediting and whether CTL/ IFN- $\gamma$-mediated immunoediting influences CNAs, here, we examined tumours expressing immunogenic antigens in the context of cytotoxic T-cell (CTL)-mediated immunoediting in vivo. Our results indicate that exposure of tumours to antigen-specific IFN- $\gamma$-producing CTL results in tumour CNAs that correlate with immune resistance.

\section{Results}

HA-specific CTLs result in HA antigen loss. We first established single-cell-derived clones of 4T1 mammary tumours that express either influenza haemagglutinin (HA) antigen (4T1-HA), HA and a dominant-negative form (DN) of the IFN- $\gamma$ receptor (IFN- $\gamma \mathrm{R}$ ) (4T1-HA $\gamma \mathrm{RDN})$ or HA and control vector (4T1-HAc). These 4T1-derived tumour clones expressed equivalent levels of HA and MHC class I, and equally induced HA-specific CTL in vivo, and equally re-stimulated HA-specific CTLs in vitro, despite the impaired IFN- $\gamma$ responsiveness of $4 \mathrm{~T} 1-\mathrm{HA} \gamma \mathrm{RDN}$ cells (Fig. 1a-c; Supplementary Fig. 1a-d). These results indicate the equivalent HA antigenicity of each 4T1 clone. The phosphorylation of STAT1 in 4T1-HAc cells, but not 4T1-HA $\gamma$ RDN cells, in response to adoptive wild type (WT), but not IFN- $\gamma^{-/-}$, CTL transfer (ACT) into $R A G^{-Y-}$ mice demonstrated that 4T1-HA cells responded to IFN- $\gamma$ produced by HA-specific CTL in vivo (Fig. 1d; Supplementary Fig. 1e,f).

A loss of tumour antigen expression has been reported in recurrent tumour cells resisting $\mathrm{ACT}^{28,29}$. To explore the impact of HA-specific CTL on the immunogenicity of 4T1-HA tumour cells, we analysed the HA expression of 4T1-HA cells after the in vivo growth under different immune selection conditions. While HA mRNA expression was stable in 4T1-HA cells after in vitro culture, or following growth in $R A G^{-/-}$or $I F N-\gamma^{-/-}$ mice, HA mRNA was lost in all tested 4T1-HA cells grown in vivo in the context of IFN- $\gamma$ producing HA-specific CTL over 25 days (Fig. 2a). Consistently, 4T1-HA and 4T1-HAc cells lost their surface HA protein expression upon in vivo exposure to IFN- $\gamma$-producing HA-specific CTLs (Supplementary Fig. 2a-c), and these 4T1-HA cells completely failed to stimulate HA-specific CTLs in vitro (Supplementary Fig. 2d). By contrast, 4T1-HA $\gamma$ RDN cells maintained HA protein expression and their antigenicity even following the growth in WT mice (Supplementary Figs $2 \mathrm{~b}$ and $3 \mathrm{a}, \mathrm{b}$ ) and were more sensitive to ACT with HA-specific CTL compared with 4T1-HAc cells
(Supplementary Fig. 3c). Of note, the introduction of STAT1 DN in 4T1-HA cells (4T1-HAS1DN cells) reduced the loss of HA antigenicity following CTL exposure (Supplementary Figs 1e and 4a-e), suggesting that 4T1-HA cells lose HA expression through an IFN- $\gamma$ R/STAT1-signalling pathway in response to IFN- $\gamma$ produced by HA-specific CTL in vivo.

IFN- $\gamma$-production is necessary for CTL-mediated HA gene loss. To further investigate the mechanisms underpinning loss of HA expression, we examined the status of the HA gene integrated into the tumour cell genome. While the HA gene remained intact in 4T1-HA cells grown in $I F N-\gamma^{-I}$ mice or $p f p / I F N-\gamma^{-/-}$ mice, 4T1-HA cells grown in WT mice or $p f p^{-1-}$ mice completely lost $\mathrm{HA}$ at both the level of mRNA and the genome (Fig. 2b). Importantly, ACT with WT or $p f p^{-1-}$ CTL, but not $I F N-\gamma^{-l}-$ CTL, into $p f p / I F N-\gamma^{-l}$ mice induced the loss of HA gene at the genome (Fig. 2b). By contrast, the HA gene was never lost in 4T1-HA cells cultured in vitro with recombinant IFN- $\gamma$ or grown in $R A G^{-/-}$mice treated with repeated IL-12 administration to induce systemic IFN- $\gamma$ production (Fig. 2c). Further, the HA gene was never lost in 4T1-HA cells co-cultured with $p f p^{-1-}$ HA-specific CTL or WT CTL with perforin inhibitor, concanamycin A (CMA; Supplementary Fig. 3d), or in 4T1-HA $\gamma \mathrm{RDN}$ or 4T1-HAS1DN cells grown in ACT-treated $R A G^{-/-}, I F N-\gamma^{-/-}$or IFN- $R^{-/-}$mice (Supplementary Fig. 4f).

These results suggest IFN- $\gamma$-producing HA-specific CTL within the tumour microenvironment are required for genomic rearrangements leading to the loss of the HA transgene in 4T1-HA cells. This loss of HA antigen may be one mechanism of many that contributes to immune evasion. To test if such HA gene loss could be a result of in vivo outgrowth of a very minor population within 4T1-HA cells lacking HA, we isolated and inoculated the cancer stem cell-like side population (SP) or main population (MP) of 4T1-HA cells into $R A G^{-/-}$or WT mice (Supplementary Fig. 5a,b; Supplementary Table 1). Even when the tumour developed from 50 cells of the SP of 4T1-HA cells, HA expression and gene were lost in WT mice, but not in $R A G^{-1}-$ mice, similar to the tumours developed from the MP of 4T1-HA cells inoculated in WT mice (Supplementary Fig. 5c,d). These results suggested the loss of the HA transgene in immune-resistant 4T1-HA cells was critically dependent upon IFN- $\gamma$, and CTL-mediated cytotoxicity alone was not sufficient since ACT with IFN- $\gamma$-deficient HA-specific CTL, that have perforinmediated cytotoxic activity intact, did not lead to HA gene loss. Moreover results suggest that loss of the HA transgene occurred during in vivo growth rather than as the result of the selective expansion of pre-existing $\mathrm{HA}$ gene negative cells within the 4T1-HA cells.

IFN- $\gamma$-producing CTL results in CNAs in 4T1-HA tumour cells. To further explore the possible contribution of genetic alteration to HA gene loss in 4T1-HA tumour cells, we performed array-based comparative genome hybridization (a-CGH) analysis of 4T1-HAc and 4T1-HA $\gamma \mathrm{RDN}$ cells grown in vitro and in vivo (Fig. 3a; Supplementary Fig. 6a). Importantly, no significant genomic alterations were observed in either 4T1-HAc or $4 \mathrm{~T} 1-\mathrm{HA} \gamma \mathrm{RDN}$ cells after one month of in vitro culture, indicating that the genomes of these cells were stable in vitro. By contrast, when these tumour cells were grown subcutaneously for one month under immunological pressure in immunocompetent WT mice, CNAs were observed in 4T1-HAc cells, but not 4T1-HA $\gamma$ RDN cells. Notably, although few CNAs were observed in 4T1-HAc cells grown in immune-deficient $R A G^{-1-}$ mice or IFN- $\gamma^{-1-}$ mice, ACT of HA-specific CTL into these 


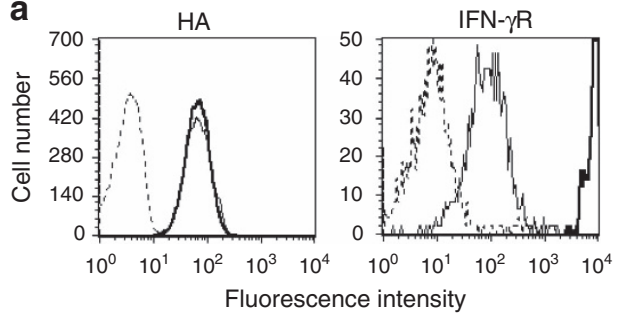

b

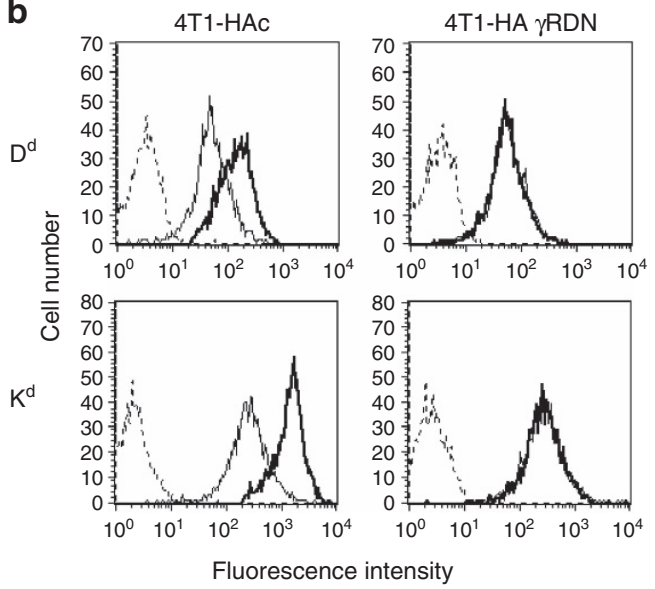

C

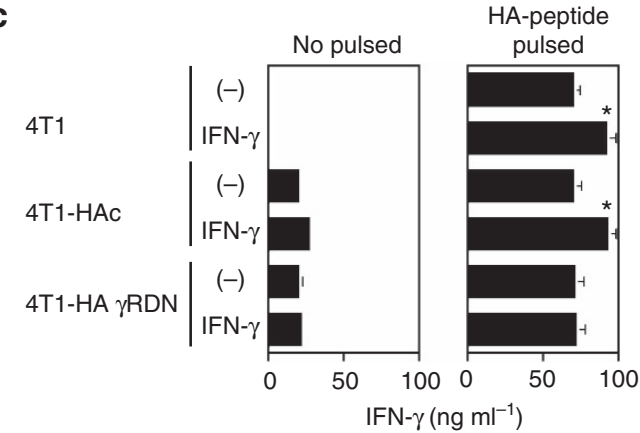

d
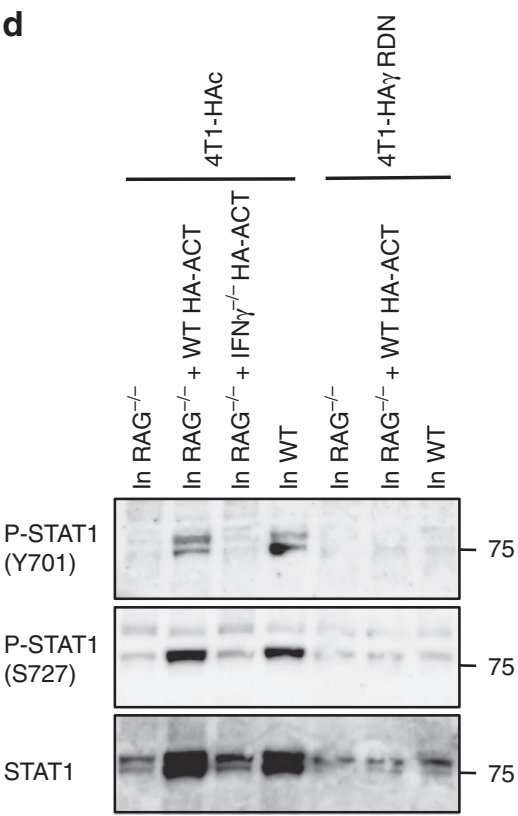

P-STAT3 (Y705)

STAT3

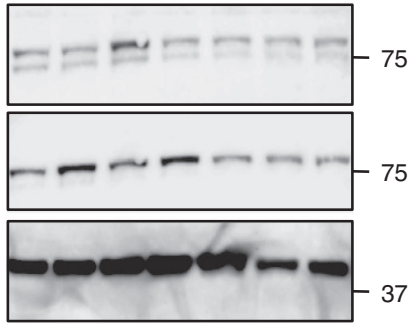

$\beta$-actin

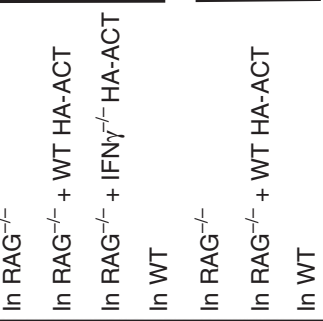
t5 
a
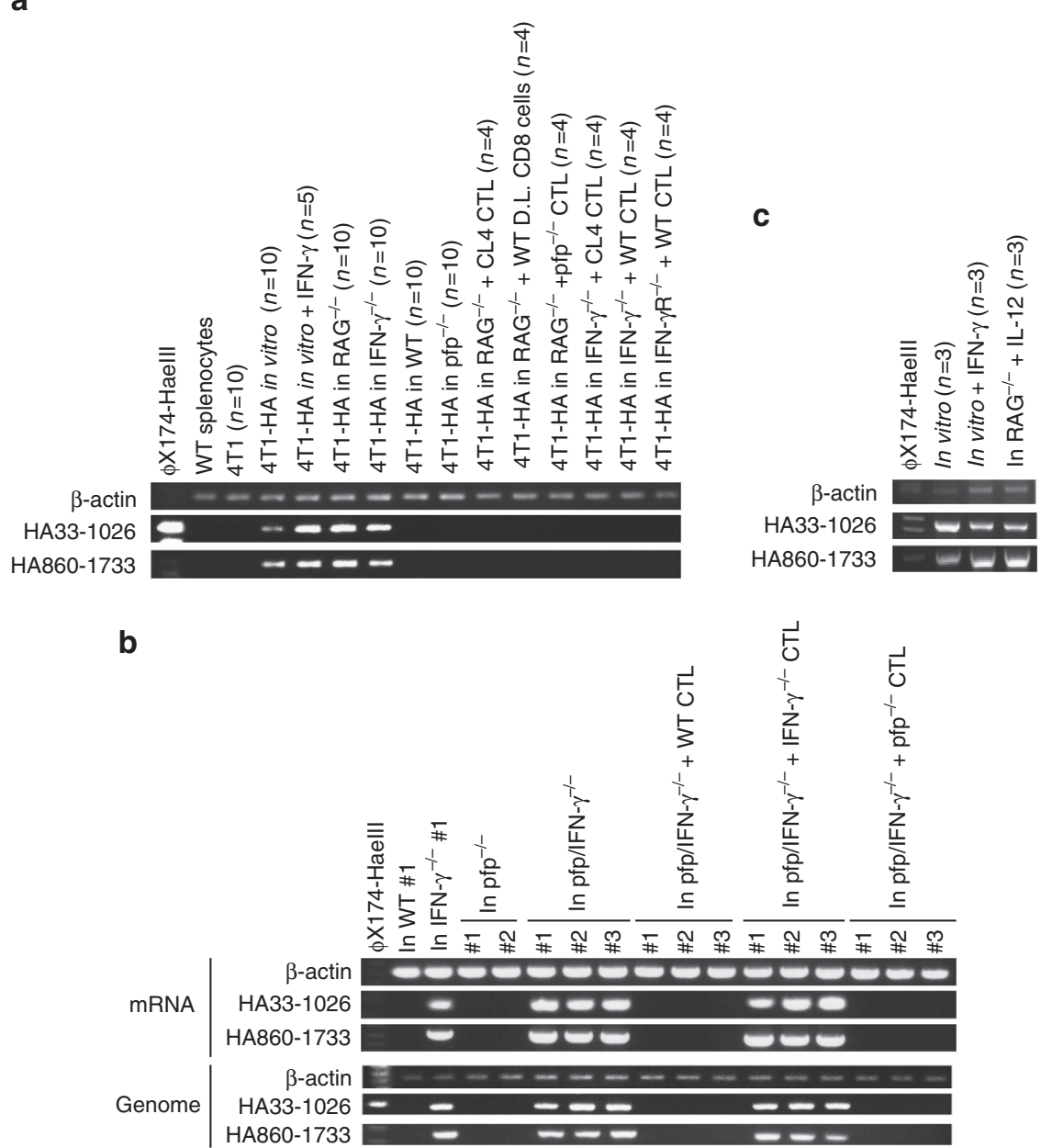

Figure 2 | Integrated HA gene loss in 4T1-HA cells responding to IFN- $\boldsymbol{\gamma}$ and CTL in vivo. (a) mRNA was prepared from WT splenocytes, 4T1 cells cultured in vitro, and representative HA-positive and HA-negative 4T1-HA cells isolated after the growth under the indicated conditions, then the indicated segments of HA gene were amplified by RT-PCR. RT-PCR was performed on every 4T1-HA cells independently, and the indicated number of PCR products were mixed and loaded in the respective groups. (b) Genome DNA and mRNA were prepared from 4T1-HA cells grown in the indicated mice for 25-35 days, and the indicated segments of the HA gene were amplified by RT-PCR and genomic PCR. (c) Genome DNA was prepared from three 4T1-HA cells grown independently in vitro with or without IFN- $\gamma$ or in IL-12-treated $R A G^{-/}$- mice for 30 days, and the indicated segments of the HA gene were independently amplified by genomic PCR. PCR products were mixed and loaded in the respective groups. Similar results were obtained in two independent experiments in all presented experiments (a-c).

Moreover, kinetic analysis indicated that CNAs accumulate during immunological selection (Supplementary Fig. 7a) and lead to the intra-tumour heterogeneity accompanied by tumour antigen gene loss in 4T1-HA cells (Supplementary Fig. 7b). These results suggest that HA gene loss occurs when CTL and CTL-derived IFN- $\gamma$ resulted in increased CNAs in 4T1-HA cells in the tumour microenvironment.

CNAs in OVA-expressing EG7.1 cells exposed to CTL in vivo. To clarify whether CNA induction and/or tumour-antigen loss was a cell-type or antigen-specific effect, we next established a single cell-derived clone (EG7.1) from OVA-expressing EG7 lymphoma cells and an EG7.1-derived single cell clone expressing DN of IFN- $\gamma$ R (EG7.1 $\gamma$ RDN; Supplementary Fig. 8a,b). The expression of IFN- $\gamma \mathrm{R}$ DN augmented the susceptibility to ACT in $R A G^{-1-}$ mice (Supplementary Fig. $8 \mathrm{c}$ ), similar to the observation made in 4T1-HA cells. While somewhat less EG7.1 cells lost their OVA mRNA expression and OVA gene in genome through an IFN- $\gamma$-mediated immunoediting process (Fig. 4a,b), marked CNAs were frequently observed in EG7.1 cells exposed to
CTL in vivo (Fig. 5a), but not in EG7.1 cells grown in $R A G^{-1-}$ mice or OVA-expressing EG7.1 $\gamma \mathrm{RDN}$ cells grown in WT mice treated with OT-1 CTL (Fig. 5a and Supplementary Fig. 8d).

CNAs in CMS5al tumour cells exposed to CTL in vivo. To study the effect of CTLs recognizing endogenous antigens, we employed a single cell-derived clone (CMS5a1) from CMS5 cells that express spontaneously mutated extracellular signal-regulated kinase (ERK) as the endogenous tumour antigen ${ }^{29}$ and a CMS5a1-derived single cell clone expressing DN of IFN- $\gamma$ R (CMS5a1 $\gamma \mathrm{RDN})$. Again, ACT with mutated ERK (mERK)specific CTLs induced CNAs in four of six tested CMS5al cells, but not in CMS5al $\gamma$ RDN cells (Fig. 5b). Interestingly, the frequency of CNA induction was increased when ACT treatment was more extended (Fig. 5b; Supplementary Fig. 9a-c). The copynumber reduction demonstrated by a-CGH analysis was confirmed by the quantitative reverse transcription (RT)-PCR for GM1374 that is located at chromosome XA1.1 (Supplementary Fig. 9d). Unexpectedly, all tested CMS5a1 cells maintained expression of mERK mRNA (Fig. 4c). Given that 
$4 \mathrm{~T} 1-\mathrm{HAC}$

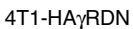

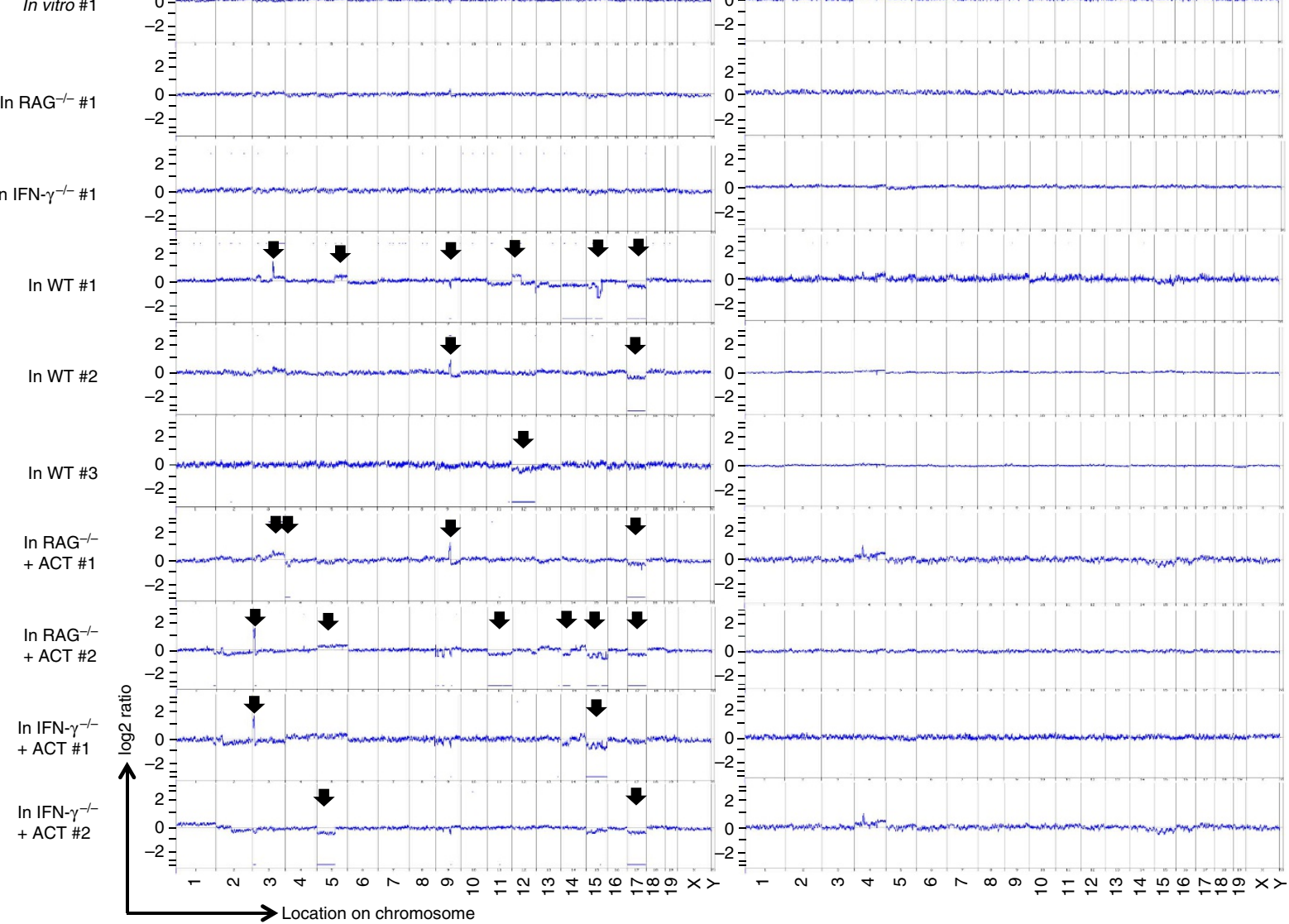

b
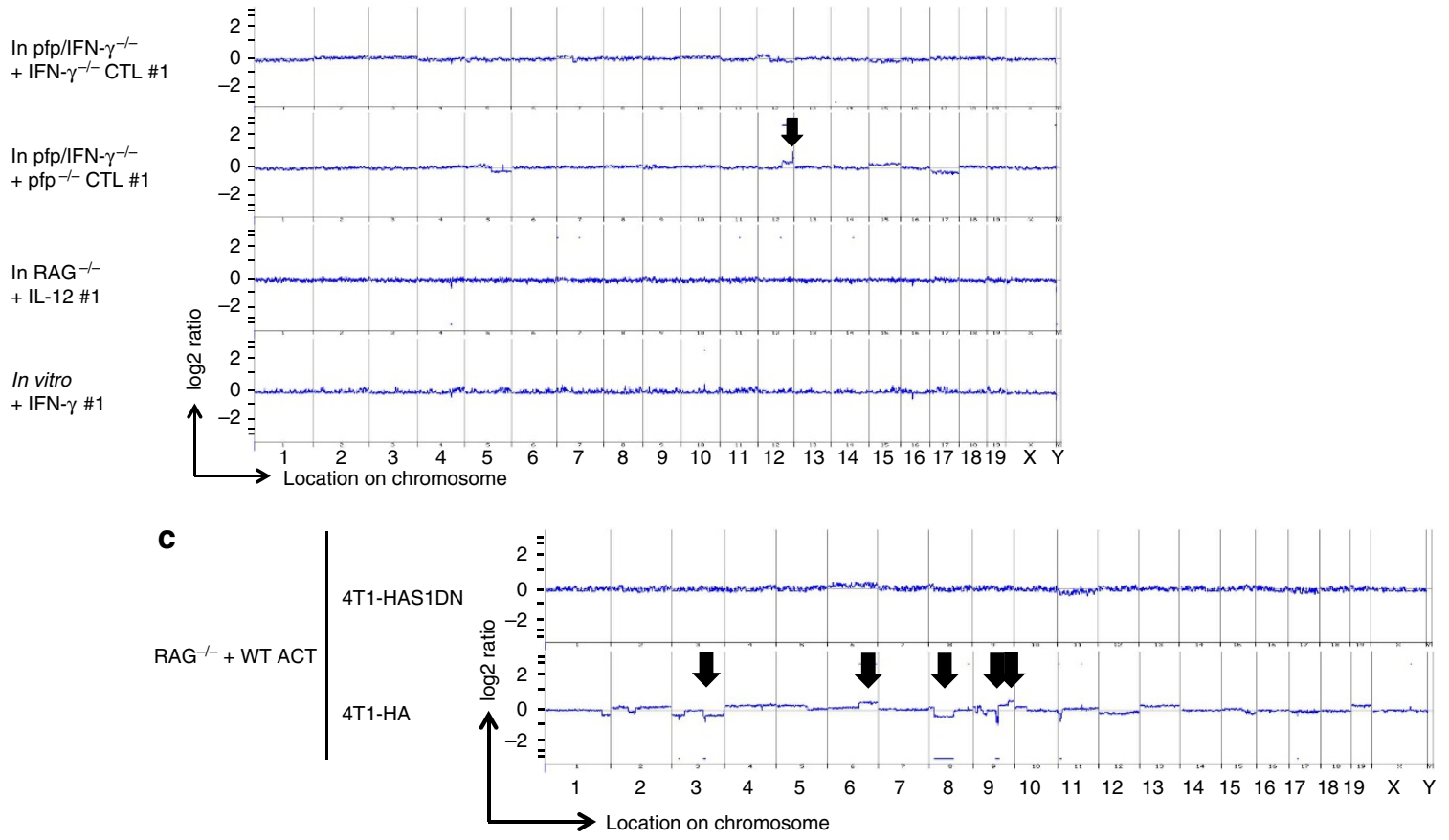

Figure 3 | Genomic alteration in 4T1-HA cells responding to IFN- $\gamma$ and CTL in vivo. Genomic DNA were prepared from 4T1-HAc and 4T1-HA $\gamma$ RDN cells that were isolated from the growing tumour mass in the indicated mice ( $>99 \%$ purity) (a) or 4T1-HAc cells isolated from the growing tumour mass in $p f p / I F N-\gamma-/-$ mice 25 days after the ACT with HA-specific IFN- $\gamma^{-/-}$or pfp ${ }^{-/-}$CTL or in IL-12-treated $R A G^{-/-}$mice at 30 days or from 4T1-HA cells cultured with IFN- $\gamma$ for 30 days in Fig. 2b,c (>99\% purity) (b). Then, CNAs were examined by a-CGH used for s.c. inoculation as the reference sample. (c) 4T1-HA cells and 4T1-HAS1DN cells were inoculated into the same $R A G^{-/-}$mice that were treated with ACT on day 0. Genomic DNAs were obtained from both tumour cells prepared from the growing tumour masses 30 days after the tumour inoculation. Then, CNAs were examined by a-CGH. In a-CGH analysis, the tumour cells used for the s.c. inoculation are the reference sample. The positions showing significant CNA are indicated by the lines and arrows. 
a
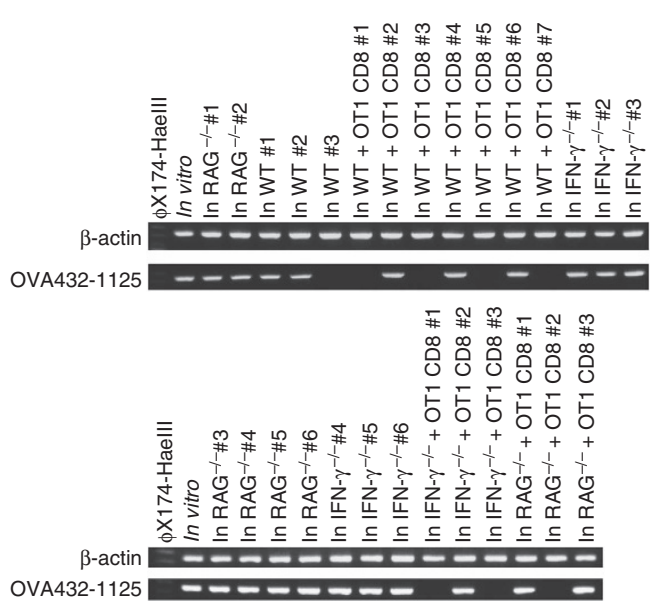

b
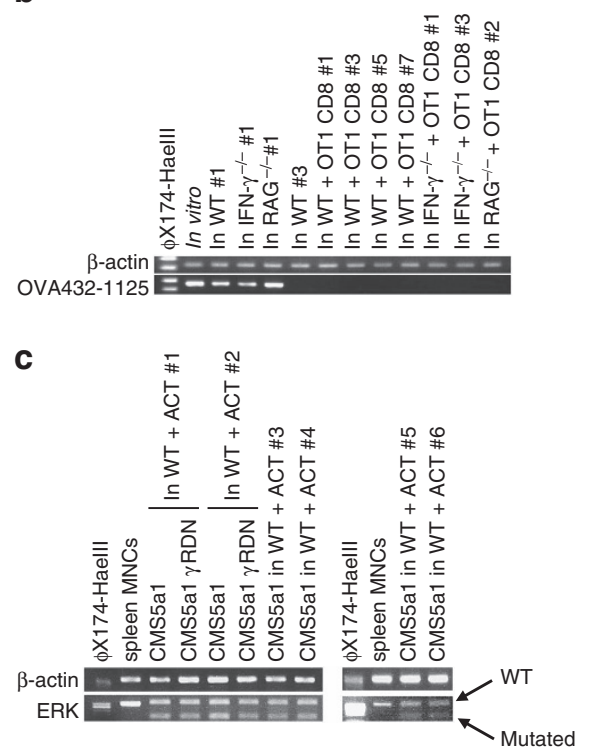

Figure 4 | Antigen gene expression in EG7.1 cells and CMS5a1 cells after the exposure to tumour-specific CTL in vivo. (a,b) EG7.1 cells were inoculated into the indicated mice, and some mice were treated with ACT of OVA-specific OT-1 CTLs on day 0. mRNA and genome DNA were prepared from EG7.1 cells grown 25-35 days. The indicated segment of the OVA gene, that contains $\mathrm{H}-2 \mathrm{~K}^{\mathrm{b}}$-restricted CTL epitope targeted by OT-1, was amplified by RT-PCR (a) or genomic PCR (b). (c) mRNA was prepared from CMS5a1 cells isolated from the growing tumour mass in the indicated mice. ERK gene was amplified by RT-PCR, then, PCR products were digested by Sfcl restriction enzyme that selectively cleaves mutated ERK, but not wild type ERK2. Similar results were obtained in two independent experiments in all presented experiments (a-c).

a

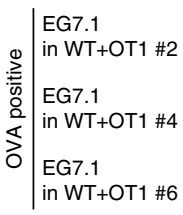

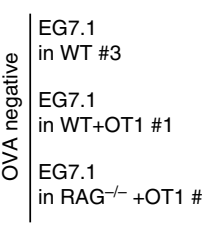

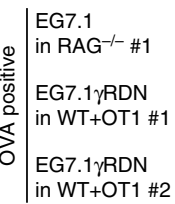

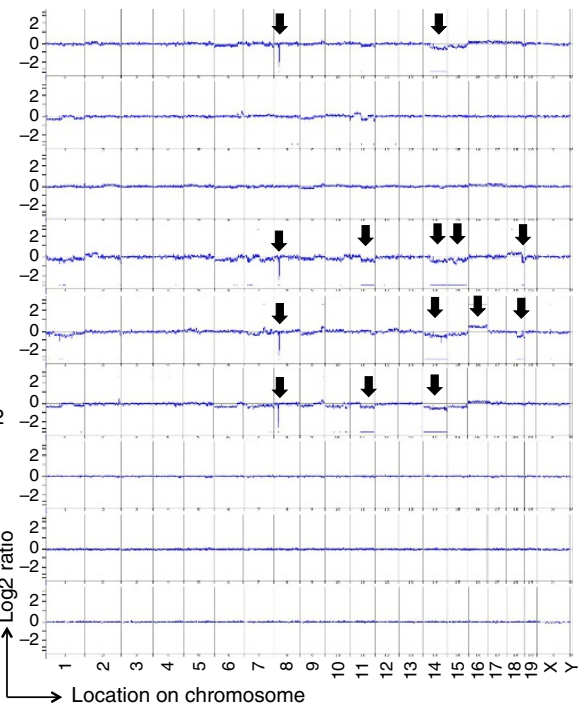

b

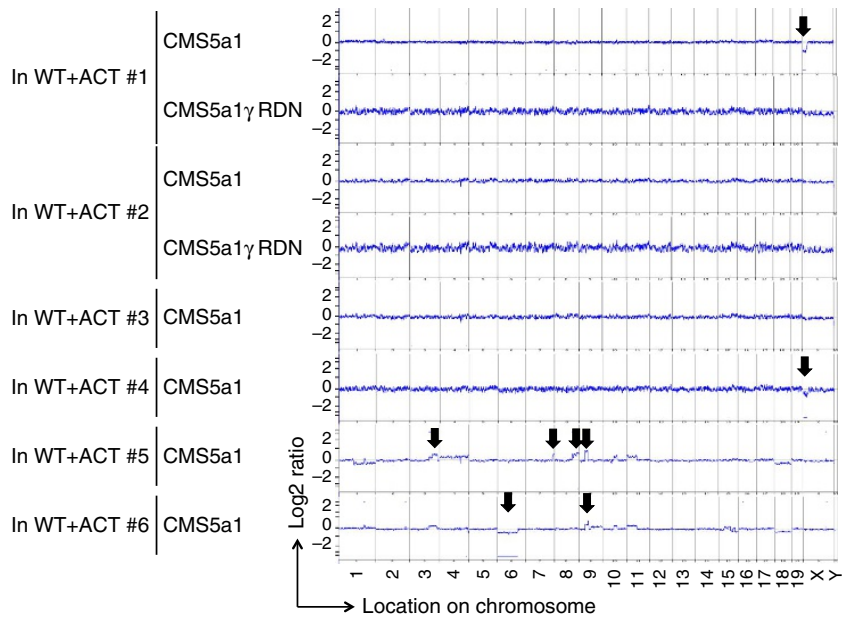

Figure 5 | Genetic alteration in EG7.1 cells and CMS5a1 cells after the exposure to tumour-specific CTL in vivo. (a) Genomic DNAs were prepared from EG7.1 cells isolated from the growing tumour mass in the indicated mice (Fig. 4a,b) and EG7.1 $\gamma$ RDN cells isolated from the growing tumour mass in OT-1treated WT mice 25 days after tumour inoculation (Supplementary Fig. 8d). Then, CNAs were examined by a-CGH employing tumour cells used for s.c. inoculation as the reference sample. (b) Genomic DNAs were prepared from CMS5a1 cells isolated from the growing tumour mass in the indicated mice as in Fig. 4c and Supplementary Fig. 9a-c. Then, CNAs were examined by a-CGH employing tumour cells used for s.c. inoculation as the reference sample. The positions showing significant CNA are indicated by the lines and arrows.

several immunoedited EG7.1 and CMS5a1 cells still expressed their antigens (Fig. 4a,c), it is likely that other mechanisms and/or modification of other gene expression by CNAs contributes to immune evasion in resistant subclones following exposure to IFN- $\gamma$ producing antigen-specific CTLs. Loss of the CTL-targeted antigen might be the most efficient method to escape from tumour-specific CTLs. However, genomic instability associated with in vivo immunological pressure is consistently observed across multiple tumour cell types, vectors, and antigens, suggesting a fundamental mechanism driving adaptive evolution under immune selection. The distinct results with the CMS5a1 cells suggest that perhaps the transfected antigen systems show 
bias towards antigen loss or longer timeframes are required with endogenous neo-antigens to witness a higher frequency of antigen loss.

IFN- $\gamma$-producing CTL effect on DNA damage and repair pathways. We observed a variable pattern of expression of genes implicated in DNA repair and maintenance by quantitative RT-PCR. The Apobec family is implicated in tumour diversity and subclonal evolution ${ }^{30}$. Apobec3 expression was reported to be positively regulated by STAT1 (ref. 31). Consistently, Apobec3, as well as Apobec1, expression was increased in 4T1-HA and CMS5a1 cells compared with controls expressing IFN $-\gamma \mathrm{R} D N$, and gene expression in CMS5a1 cells was augmented upon ACT (Fig. 6a). Several other genes implicated in DNA repair and maintenance were reduced in 4T1-HA cells compared with 4T1-HAS1DN cells grown in ACT-treated $R A G^{-/-}$mice
(Fig. 6b). However, DNA repair gene expression in CMS5a1 cells grown in $R A G^{-1-}$ mice was not significantly modulated by ACT (Fig. 6b), but double strand breaks (measured by the number of phospho-Histone H2A.X (Ser139)( $\gamma \mathrm{H} 2 \mathrm{~A} . \mathrm{X})$-foci) were significantly increased in CMS5al cells, but not in CMS5a1 $\gamma$ RDN cells, grown in $R A G^{-1-}$ mice upon ACT $(P<0.05$ by unpaired, two-tailed Student's $t$-test)(Supplementary Fig. 9e,f), consistent with increased genomic instability. A reproducible reduction in expression of the double strand DNA damage-sensing gene, Atr, was confirmed by quantitative RT-PCR in 4T1-HA cells (Fig. 6c). Inactivation of ATM/ATR was reported to promote chromosomal instability ${ }^{32}$. Thus, we examined the effect of a small molecule inhibitor of ATR (VE822) on immune-induced genomic instability (Fig. 7a). Significant CNAs were induced in CMS5al cells upon ACT combined with VE822 treatment (Fig. 7b), which were not observed in CMS5a1 cells grown in ACT-treated or VE822-treated $R A G^{-1-}$ mice. All tested CMS5al cells retained a

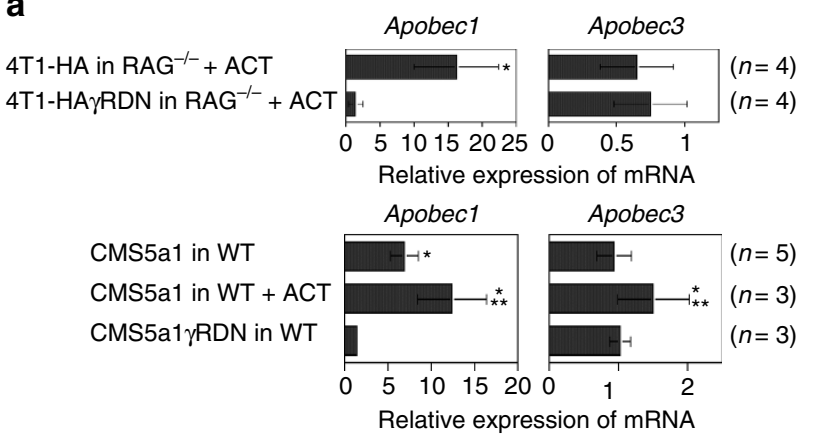

C

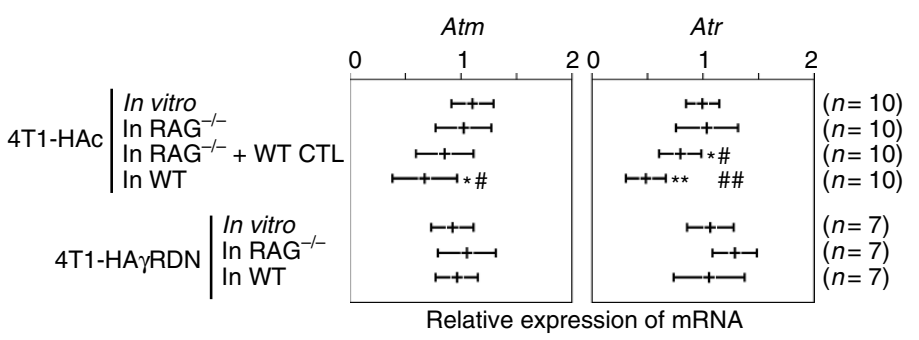

b

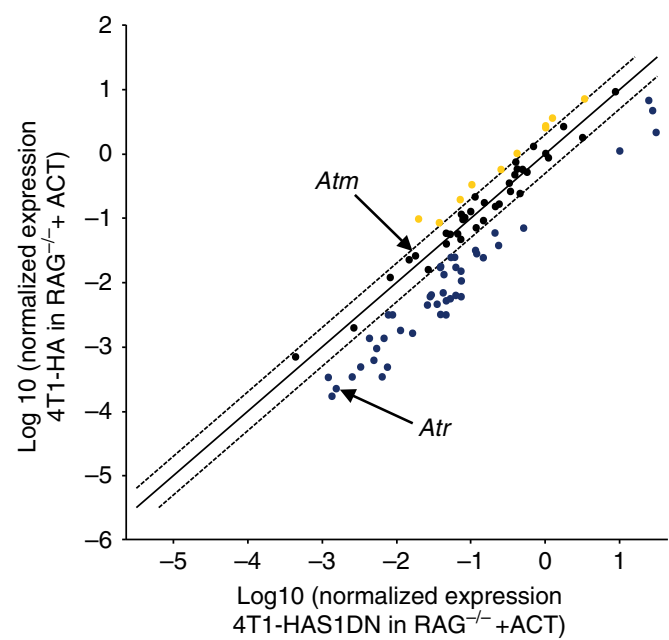

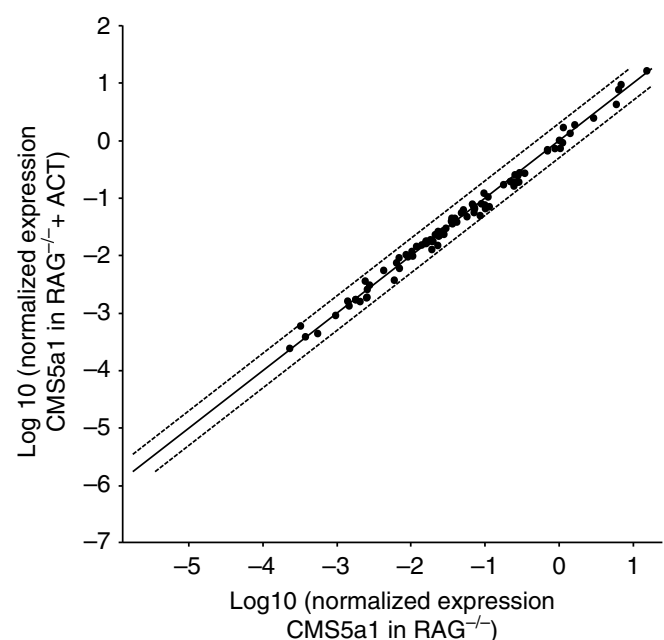

Figure 6 | Altered expression of genes implicated in DNA repair and maintenance in tumour cells exposed to CTL-mediated immunoediting.

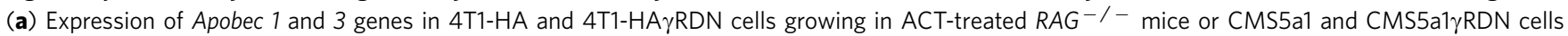
growing in WT or ACT-treated WT mice. The gene expression was normalized to $\beta$-actin levels, and the relative expression compared with the respective cells grown in $R A G^{-/-}$mice (in upper panels) or respective in vitro cultured cells (in lower panels). Results are indicated as the average $\pm \mathrm{s}$.d. of the results obtained from the experiments using the numbers of tumour cells indicated in parentheses. ${ }^{\star} P<0.05$ compared with IFN- $\gamma R$ DN expressing respective cells; ${ }^{\star \star} P<0.005$ compared with CMS5a1 cells grown in WT mice. Both are analysed by unpaired, two-tailed Student's t-test. Similar results were obtained in two independent experiments. (b) mRNA was prepared from freshly isolated 4T1-HA and 4T1-HAS1DN cells grown in the same ACT-treated RAG ${ }^{-/-}$ mice $\left(n=3\right.$ each) or CMS5a1 cells grown in $R A G^{-/-}$or ACT-treated $R A G^{-/-}$mice $(n=3$ each). Expression of DNA repair genes was examined by quantitative RT-PCR array. (c) mRNA was prepared from freshly isolated 4T1-HAc and 4T1-HA $\gamma$ RDN cells growing in vitro, in RAG ${ }^{-/-}$, WT HA-specific CTL-treated $R A G^{-/-}$, and WT mice. Double strand DNA repairing protein kinase ataxia-telangiectasia and Rad3 related, Atr, and protein kinase ataxiatelangiectasia mutated, Atm, gene expression was examined by quantitative RT-PCR. The gene expression was normalized to Gapdh levels, and the relative expression compared with the mean value of the in vitro growing tumour samples is presented. Results are indicated as the average \pm s.d. of the results obtained from the experiments using the numbers of tumour cells indicated in parentheses. ${ }^{\star} P<0.05$ compared with cells in vitro; ${ }^{* \star} P<0.005$ compared with cells in vitro; ${ }^{\#} P<0.05$ compared with cells in $R A G^{-/-}$; $\# \#<0.005$ compared with cells in $R A G^{-/-}$. All are analysed by unpaired, two-tailed Student's t-test. 
a

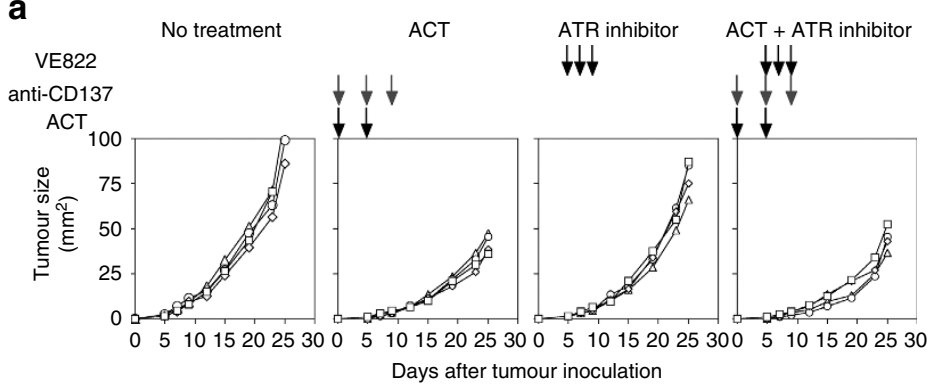

C

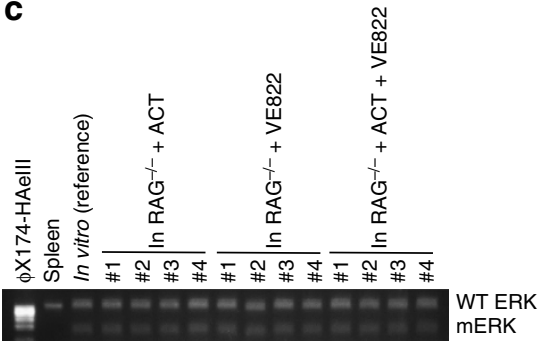

b

In $\mathrm{RAG}^{-/}+\mathrm{ACT}$

after tumour inoculation

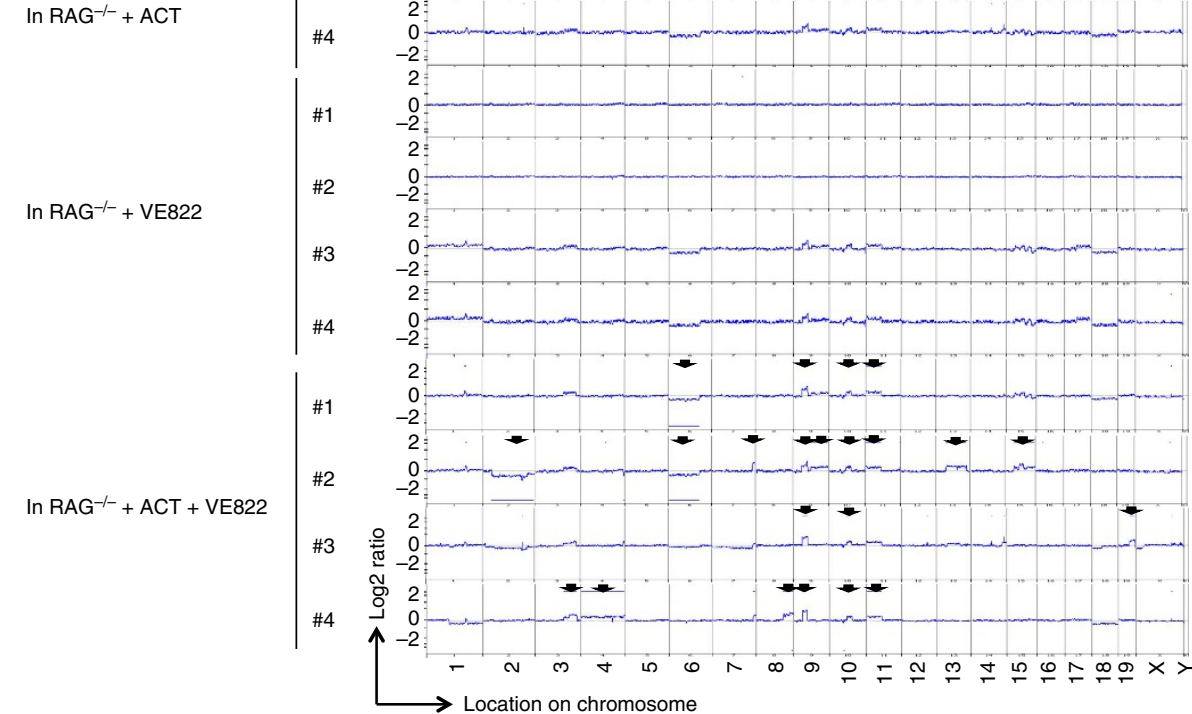

Figure 7 | CNAs induced in CMS5a1 cells in $\mathbf{R A G}^{-/-}$mice treated with ATR inhibitor and WT ACT. (a,b) CMS5a1 cells were inoculated into RAG ${ }^{-/-}$ mice, and some mice were treated with CD8 T cells prepared from DL of CMS5a1-bearing WT mice that were treated with anti-CD137 mAb as indicated by the black arrows on day 0 and 5. These ACT-treated mice were also treated with anti-CD137 mAb to activate CTL on day 0,5 and 9 as indicated by the grey arrows. Some mice were treated with ATR inhibitor, VE822, on day 5, 7 and 9 as indicated by the black arrows. Tumour growth was measured and tumour cells were isolated 25 days after tumour inoculation (a). Genomic DNA and mRNA were prepared from CMS5a1 cells isolated from the tumour mass on day 25. Then, CNAs were examined by a-CGH employing tumour cells used for s.c. inoculation as the reference sample (b). The positions showing significant CNA are indicated by the lines and arrows. mRNA of ERK gene was amplified by RT-PCR, then, PCR products were digested by Sfcl restriction enzyme that selectively cleaves mutated ERK, but not wild type ERK2 (c). Concerning tumour growth and HA expression at RNA level, similar results were obtained in two independent experiments.

their endogenous tumour antigen (mERK) expression (Fig. 7c). Collectively, these results suggest that CTL and CTL-derived IFN- $\gamma$ may induce genomic instability through the modulation of DNA damage responses and repair pathway in tumour cells in vivo.

CNAs in IFN- $\gamma$-producing 4T1-HA cells. To further address the importance of microenvironment on CTL-induced genetic instability, we inoculated IFN- $\gamma$-overexpressing 4T1-HA cells into $R A G^{-1-}$ mice treated with CTL. We established IFN- $\gamma$ producing single cell-derived clones (4T1-HAIFN $\gamma \mathrm{Tf}$ ) from 4T1-HA cells. 4T1-HAIFN $\gamma$ Tf produced $>1.1 \mu \mathrm{g} \mathrm{ml}^{-1}$ of IFN- $\gamma$ when cells were cultured in vitro for $16 \mathrm{~h}$ at $5 \times 10^{5}$ cells per $200 \mu \mathrm{l}$. $4 \mathrm{~T} 1-\mathrm{HAIFN} \gamma \mathrm{Tf}$ cells grew slowly in vitro and in $R A G^{-/-}$mice compared with 4T1-HA cells, and never progressively grew when $2 \times 10^{6} 4$ T1-HAIFN $\gamma$ Tf cells were inoculated in WT mice $(n=6)$. We obtained genomic DNA and RNA from 4T1-HAIFN $\gamma$ Tf cells isolated from tumour masses in $R A G^{-1-}$ mice 30 days after the treatment with draining lymph node $\mathrm{T}$ cells (DL) that were harvested from 4T1-HAIFN $\gamma$ Tf cells-inoculated into WT or $I F N-\gamma^{-1}$

- mice (Fig. 8a). As expected, CNAs or HA gene loss were not observed in 4T1-HAIFN $\gamma$ Tf cells isolated from the tumour masses in $R A G^{-1-}$ mice (Fig. 8b,c). Further, marked CNAs were observed in 4T1-HAIFN $\gamma$ Tf cells that were obtained from tumour masses in $R A G^{-1-}$ mice treated with $\mathrm{CD}^{+} \mathrm{T}$ cells of WT or $I F N-\gamma^{-/}$DL cells (Fig. 8b), although these cells retained the HA RNA and HA gene (Fig. 8c). These results suggest that CNAs can be induced by antigen-specific CTLs that are impaired in IFN- $\gamma$ production, if ectopic IFN- $\gamma$ is released by tumour cells. Thus, to induce CNAs in tumour cells, IFN- $\gamma$ is critical, but does not have to be produced necessarily by tumour-specific CTL. Our findings also show that CNAs induction is not simply replicated by supplementing IFN- $\gamma$ within tumour microenvironment, rather the genetic instability is augmented in tumour cells only when IFN- $\gamma$ and CTLs co-exist in tumour microenvironment.

\section{Discussion}

IFN- $\gamma$ is regarded to play critical roles in anti-cancer immune responses by augmentation of MHC Class I expression, growth arrest $^{7}$, post-proteasomal trimming of antigen epitopes ${ }^{8}$ and recruitment of effector cells ${ }^{9}$. Moreover, the transcription factor 
a

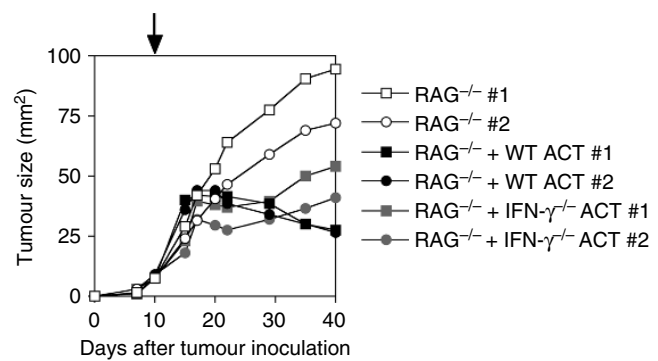

C

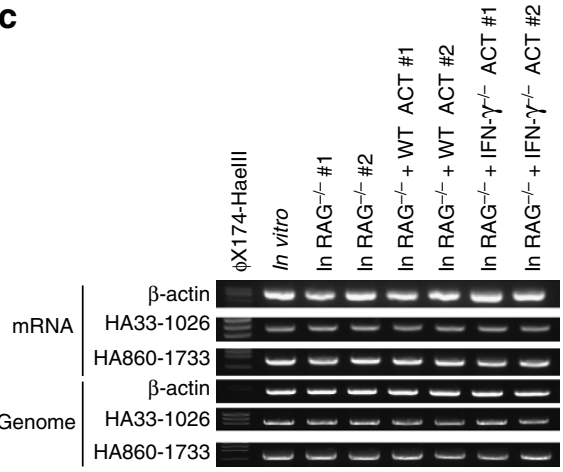

b

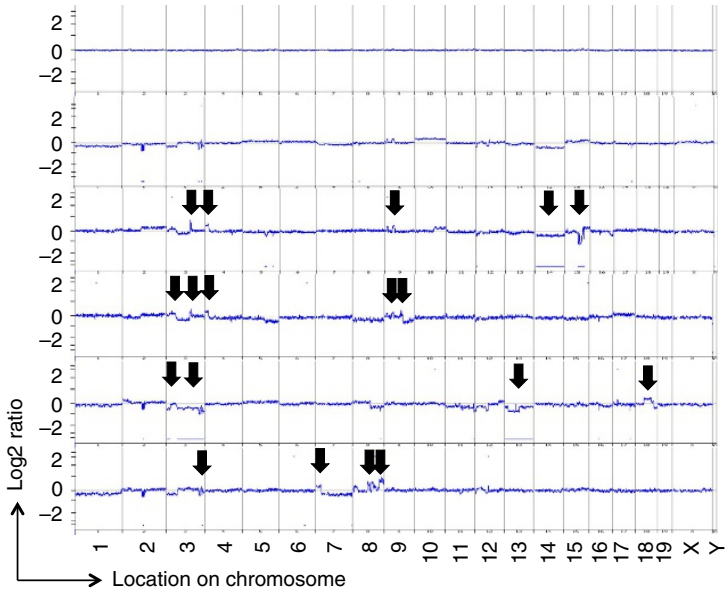

Figure 8 | CNAs induced in IFN- $\boldsymbol{\gamma}$-producing 4T1 tumours in RAG $^{-/}$- mice treated with WT or IFN- $\boldsymbol{\gamma}^{-\boldsymbol{I}}-$ ACT. $5 \times 10^{5}$ of 4 T1-HA cells producing high amount of IFN- $\gamma$ (4T1-HAIFN $\gamma$ Tf) were inoculated into $R A G^{-/-}$mice. As indicated by arrow, when palpable tumours developed after 10 days, mice were received T cells $\left(5 \times 10^{7}\right.$ per mice) obtained from draining lymph node of WT or IFN- $\gamma^{-/}$- mice that were inoculated with 4 T1-HAIFN $\gamma$ Tf cells 7 days before the sacrifice. Tumour cells were isolated from tumour mass 30 days after ACT (a), and genomic DNAs and mRNAs were prepared. CNAs were examined by a-CGH employing tumour cells used for s.c. inoculation as the reference sample (b). The positions showing significant CNA are indicated by the lines and arrows. The indicated portion of the HA gene were amplified by RT-PCR and genomic PCR (c). Concerning tumour growth and HA expression at RNA level, similar results were obtained in two independent experiments.

interferon regulatory factor (IRF)-1 was reported to manifest tumour-suppressor activity in tumour cells ${ }^{10}$. Consistently, we have also reported important roles of IFN- $\gamma$ in tumour-rejecting CTL functions ${ }^{33}$ and NK cell-mediated anti-metastatic effects $^{34,35}$. By contrast, it was also reported that IFN- $\gamma$ appreciably contributes to aberrant DNA methylation ${ }^{16}$, tumour initiation $^{12}$, survival and outgrowth ${ }^{13}$. Another very recent study showed that prolonged IFN signalling in tumour cells increased resistance to immune checkpoint blockade through multiple inhibitory pathways ${ }^{36}$. Notably, it was reported that IFN- $\gamma$ promotes an immune suppressive microenvironment during MCA-induced carcinogenesis, but conversely promotes anti-tumour immune responses against transplanted MCAinduced sarcomas ${ }^{19}$. In MCA-induced fibrosarcoma models, immunoediting has been confirmed ${ }^{3}$ and IFN- $\gamma$ responsiveness of tumour cells was reported to be critical to anti-tumour immune responses ${ }^{11}$. Thus, the roles of IFN- $\gamma$ in tumour development and growth are variable and complex depending upon the tumour model, phase of tumour development, and success of immune selection pressure. Moreover, tissue microenvironment (niche) appears to be important for the biological and genetic progression of malignancy ${ }^{37}$. Our data herein suggest that tumour cells adapt in the context of host immune responses and the microenvironment. Tumours develop heterogeneity and progress to escape variants with greater malignancy ${ }^{38}$, not only by epigenomic or post-transcriptional alterations, but also by promoting genetic instability with CNAs.

The genomic instability induced by CTL and IFN- $\gamma$ during tumour progression in this study is in the context of tumour adaptation rather than initiation. These mutations in some circumstances confer an immunoevasive growth advantage, metastatic potential and therapeutic resistance ${ }^{24}$. Interestingly, genomic instability was consistently observed in all-tested tumour cells, however, loss of target antigen was not observed in CMS5a1 cells. This suggests that increased genetic diversity generated by immunological genomic instability favours the stochastic emergence of resistant genotypes, which is sometimes associated with loss of antigen, but is alternatively sometimes due to other unknown mechanisms. The preservation of the ERK mutation in CMS5a1 cells may be due to counter-selection for the growth advantage associated with this growth signalling kinase. Presumably there are multiple possible routes to immune evasion, the favouring of which is dependent on a balance of selective pressures and stochastic events.

We show that CTL/IFN- $\gamma$ promoted genetic alteration in tumour cells and the frequency of such genetic alteration was associated with their immunogenicity. What is the molecular link between $\mathrm{CD}^{+} \mathrm{T}$ cells and IFN- $\gamma$ production to genomic alteration in tumour cells? Understanding this final molecular step is critical, and identifying such would represent a critical advance in the field. We hypothesize that these processes are 
relevant to the immunoediting process during an immune:cancer equilibrium $^{1}$, when many de novo tumours express non-self endogenous rejection antigens ${ }^{3,4}$. CTL-induced alteration of genetic diversity might arise relatively early during carcinogenesis, generating a 'Cambrian' explosion of subclones characterized by gross genomic instability. Consistent with this, a single-cell DNA sequencing method recently suggested that large-scale structural changes in the genome, rather than point mutations, possibly occur early in tumour development ${ }^{39}$. It was also recently reported that majority of CNAs were acquired in short punctuated bursts at the earliest stages of tumour evolution $^{25-27}$. Other mechanisms may apply at later phases of tumour progression, where CTL-secreted IFN- $\gamma$ induces stem cell proliferation $^{15}$ and PD-L1 expression on tumour cells ${ }^{14}$. It was also reported that melanoma cells reversibly downregulate melanocytic lineage antigens responding to TNF- $\alpha$ produced by CTL following therapy ${ }^{40}$. Together, these data suggest a dynamic multifactorial interaction between cancer cells and anti-tumour CTL throughout tumour development, despite the fact that anti-tumour CTL are generally critical suppressors of tumour development.

Tumours often eventually relapse after transient suppression following ACT therapy with tumour-associated antigen-specific $\mathrm{CTL}^{41}$, suggesting that tumour cells are able to acquire resistance by downregulating their immunogenicity $28,40,42$ or by inducing $\mathrm{T}$-cell tolerance ${ }^{14,43}$. The results presented here suggest that the induction of genomic instability may lead to resistance to immunotherapies. On the other hand, neo-antigen expression, mutations in driver genes, and CNAs of gene loci containing immune regulators were associated with the expression of immune cytolytic molecules in human tumours ${ }^{44}$. Considering tumours that are susceptible to immune checkpoint-targeting therapies bear higher levels of somatic mutations possibly due to the exposure to strong carcinogens ${ }^{45}$, genomic alterations not only result in the induction of neo-antigens that can drive immune responses, but paradoxically drive immune-evasion.

CTL expressing high-avidity antigen-specific T-cell receptor recognizing antigen with high affinity for MHC Class I are critical for the effective immune therapies ${ }^{46,47}$. Such strong immunotherapies also induce antigen-negative variants, thus, combination with additional therapies is required to overcome the escape ${ }^{47}$. Our findings possibly support a theoretical advantage of combining immune therapies targeting 'oncoantigens' that play critical roles for tumour cell maintenance and growth ${ }^{48}$, with therapies targeting genomic repair and maintenance mechanisms. The increased dependency of cancer cells on genomic instability following exposure to immunotherapies may render cancer cells more susceptible to DNA damage-inducing chemotherapies and/ or radiotherapies, or the increasing suite of drugs targeting DNA repair and maintenance.

\footnotetext{
Methods

Mice. Six- to 8-week-old wild-type (WT) BALB/c and C57BL/6 mice were from Charles River Japan Inc. (Yokohama, Japan) and The Walter and Eliza Hall Institute of Medical Research (Melbourne, Australia). BALB/c IFN- $\gamma$-deficient $\left(I F N-\gamma^{-1-}\right)$, TNF-related apoptosis-inducing ligand (TRAIL)-deficient $\left(T R A I L^{-1-}\right)$, perforin-deficient $\left(p f p^{-/-}\right)$, and perforin- and IFN- $\gamma$-deficient $\left(p f p / I F N-\gamma^{--}\right)$mice were derived as described previously ${ }^{33,34,49}$. BALB/c Rag-2-deficient $\left(R A G^{-l-}\right)$ mice were provided from the central Institute for Experimental Animals (Kawasaki, Japan $)^{50}$. BALB/c IFN- $\gamma$ receptor deficient $\left(I F N-\gamma R^{-1-}\right)$ mice were derived from Jackson Laboratory (Bar Harbor, ME, USA) ${ }^{51}$. BALB/c H-2K ${ }^{\mathrm{d}}$-restricted HA-specific TCR transgenic (CL4) mice $^{52}$ were bred at the Peter MacCallum Cancer Centre. C57BL/6 Rag-2-deficient $\left(R A G^{-/-}\right)$and $\mathrm{H}-2 \mathrm{~K}^{\mathrm{b}}$-restricted OVA-specific TCR transgenic (OT-1) mice were bred at Juntendo University ${ }^{50}$. $\mathrm{H}-2 \mathrm{~K}^{\mathrm{d}}$-restricted mutated ERK2 kinase protein (mERK)-specific TCR transgenic (DUC18) mice were bred at Mie University ${ }^{29}$. All mice were maintained under specific pathogen-free conditions and used in accordance with the institutional guidelines of Juntendo University, the Peter MacCallum Cancer Centre or Mie University. Number of female mice used for the experiments was decided based on
}

historical controls. No mice were excluded based on pre-established criteria in this study and no active randomization or blinded classification was applied to experimental groups. All experiments were approved by Juntendo University, the Peter MacCallum Cancer Centre or Mie University. The variance was similar between groups when applying statistical analysis in each experiment.

Tumour cells. 4T1 mammary tumour cells (purchased from ATCC) expressing the influenza HA gene were generated by the retroviral transfection with MSCV-IRESGFP vector containing HA cDNA from the Mount Sinai strain of the PR8 influenza virus $^{52}$. HA protein expression on the cell surface was confirmed by flow cytometric analysis using HA-specific mAb, H18 (ref. 52), and PE- or eFluor 660-conjugated $\mathrm{F}\left(\mathrm{ab}^{\prime}\right)_{2}$ fragment of goat anti-mouse IgG polyclonal antibody (eBioscience, San Diego, CA). Single cell-derived clone cells were established by single cell cloning following cell sorting using FACS aria (BD Bioscience, San Jose, CA). 4T1-HA cells expressing high level of the dominant-negative form (DN) of mouse IFN- $\gamma$ receptor (IFN- $\gamma \mathrm{R}$ ) $\alpha$ chain (IFN- $\gamma \mathrm{R} 1)$ were established by the transfection with the pEF2.mu $\gamma \mathrm{R}$ plasmid containing the truncated murine IFN- $\gamma \mathrm{R} \alpha$ chain $\mathrm{cDNA}^{35,53}$. Control 4T1-HA cells (4T1-HAc) were established by transfection with the empty pEF2 vector. IFN- $\gamma$ R1 expression levels were examined by flow cytometric analysis using biotin-conjugated rat anti-mouse CD119 mAb (2E2) and PE-conjugated streptavidin (eBioscience). Then, single cell-derived clone cells were established as described above. Expression plasmids (pCAGGS-Neo) containing DN of STAT1 cDNA was kindly provided by Dr Koichi Nakajima (Department of Immunology, Osaka City University Graduate School of Medicine, Osaka, Japan) ${ }^{54}$. These were transfected into 4T1-HA cells using Amaxa Nucleofector (Lonza, Basel, Switzerland) according to the manufacturer's instructions to obtain 4T1-HA cells expressing high levels of DN of STAT1 (4T1-HAS1DN). Control 4T1-HA cells (4T1-HAPCAV) were established by transfection with the pCAGGS-Neo vector. Single cell-derived clone cells were established by single cell cloning with geneticin (G418), and overexpression of DN STAT1 was confirmed by RT-PCR and immunoblot as previously described ${ }^{54}$. 4T1-HA cells expressing high level of IFN- $\gamma$ were established by retroviral transfection using the pMXs-IRES-Puro vector harbouring the mouse IFN- $\gamma$ gene Single cell-derived clone cells (4T1-HAIFN $\gamma \mathrm{Tf}$ ) were established and abundant IFN- $\gamma$ production was confirmed using mouse IFN- $\gamma$ specific enzyme-linked immunosorbent assay (ELISA) kit (Quantikine; R \& D systems, Minneapolis, MN) according to the manufacturer's instructions. EG7.1 cells were established from EG7 cells (purchased from ATCC) by single cell cloning followed by the confirmation of stable OVA gene expression by RT-PCR. EG7.1 cells expressing high levels of DN mouse IFN- $\gamma$ R1 (EG7.1 $\gamma$ RDN cells) were established as described above. Single cell-derived clone cells were established by single cell cloning as described above. CMS5al cells were established from CMS5a cells (that were kindly provided from Dr Hiroshi Shiku, Mie University, Mie, Japan) by single-cell cloning followed by the confirmation of stable mERK gene expression by RT-PCR. CMS5al cells expressing high levels of DN mouse IFN- $\gamma$ R1 (CMS5a1 $\gamma$ RDN cells) were established as described above. Single-cell-derived clone cells were established by single-cell cloning as described above. All tumour cells used in this study were tested and authenticated negative for mycoplasma contamination.

Flow cytometric analysis. Flow cytometric analyses were performed on FACSCalibur (BD Bioscience) following Immunofluorescence staining ${ }^{34}$. PE-conjugated anti-mouse $\mathrm{H}-2 \mathrm{~K}^{\mathrm{d}}$ mAb (SF1-1.1), anti-mouse $\mathrm{H}-2 \mathrm{D}^{\mathrm{d}}$ mAb (34-2-12) (BD Bioscience), and isotype-matched control mAbs (eBM2a; eBioscience) were used to examine MHC class I expression levels on 4T1-HA and 4T1-HA IFN $\gamma$ RDN cells.

Transplantation and preparation of tumour cells. Tumour cells $\left(2-5 \times 10^{5}\right.$ per mice) were subcutaneously (s.c.) inoculated into the mice and the tumour size was measured periodically with a caliper as the product of two perpendicular diameters $\left(\mathrm{mm}^{2}\right)$. Single-cell suspensions from solid tumours were prepared using collagenase (Wako Pure Chemicals, Osaka, Japan) ${ }^{55}$, then CD $45^{+}$cells and CD $31^{+}$ cells were depleted using anti-PE MicroBeads and mouse CD45 MicroBeads on autoMACS (Miltenyi Biotec, Bergisch Glabach, Germany) following incubation with PE-conjugated anti-mouse CD31mAb (MEC13.3; BioLegend) according to the manufacturer's instructions. Freshly isolated tumour cells (purity $>90 \%$ ) were used for the analysis of genome maintenance factors by RT-PCR and flow cytometric analysis. Isolated tumour cells were cultured for $>10$ days in vitro and HA expression was confirmed by flow cytometric analysis. These were then used for the co-culture with lymphocytes, transduced HA or OVA gene expression analysis by RT-PCR, or genomic DNA analysis (purity $>99 \%$ ). In some experiments, 4T1-HA cells were cultured in vitro with $100 \mathrm{ng} \mathrm{ml}^{-1}$ of IFN- $\gamma, 10 \%$ cell-free supernatant of concanavallin A (Con A) (Sigma, St Louis, MO) stimulated WT splenocytes $\left(5 \mu \mathrm{g} \mathrm{ml}^{-1}\right), 10 \%$ cell-free supernatant of CL4 CTL co-cultured with HA-pulsed WT mouse bone marrow-derived dendritic cells (BMDC; CD8 ${ }^{+}$ cells: $\mathrm{BMDC}=10: 1)$ for 5 days in the presence of HA peptide $\left(1 \mu \mathrm{g} \mathrm{ml}{ }^{-1}\right)$ and IL-2 $\left(200 \mathrm{ng} \mathrm{ml}^{-1}\right)$, or $p f p^{-/-}$HA-specific CTL for 25 or 30 days (4T1-HA cells: $\mathrm{CTL}=10: 1)$ or WT CTL with perforin inhibitor, concanamycin A (CMA; $50 \mathrm{nM}$; Wako Pure Chemicals), (4T1-HA cells: CTL $=10: 1$ ) for 60 days. In some experiments, tumour cells were pulsed with $\mathrm{H}-2 \mathrm{~K}^{\mathrm{d}}$-restricted HA epitope peptide 
$\left({ }^{533}{ }^{2 Y S T V A S S L}{ }^{541}\right.$; Invitrogen, Carlsbad, CA, USA; $\left.1 \mu \mathrm{g} \mathrm{ml}^{-1}\right)$ for $24 \mathrm{~h}$ before the co-culture and used as stimulator cells for HA-specific CTL.

Induction of HA-specific or OVA-specific CTL. BMDC were prepared form $\mathrm{BALB} / \mathrm{c}$ WT mice with granulocyte/macrophage-colony-stimulating factor (eBioscience) $^{56}$, and cultured with LPS (Sigma, St. Louis, MO; $2 \mu \mathrm{g} \mathrm{ml}^{-1}$ ) and $\mathrm{H}-2 \mathrm{~K}^{\mathrm{d}}$-restricted HA epitope peptide (Invitrogen; $1 \mu \mathrm{g} \mathrm{ml}^{-1}$ ) overnight in RPMI1640 (Nissui Pharmaceutical, Tokyo, Japan) supplemented with $0.2 \mathrm{mM} \mathrm{L-}$ glutamine (Wako), $25 \mathrm{mM} \mathrm{NaHCO}_{3}$ (Wako), 10\% heat-inactivated fetal calf serum (FCS; JRH biosciences, Lenexa, KA), and $5 \times 10^{-5} \mathrm{M} \beta 2$-mercaptoethanol (Wako) at $37^{\circ} \mathrm{C}$ in a $5 \%$ carbon dioxide humidified atmosphere ${ }^{57}$. The nylon non-adherent cells were enriched from freshly isolated splenic MNCs of CL4 mice using a nylonwool column (Wako Pure Chemicals, Osaka, Japan), and cells $\left(2.5 \times 10^{6}\right.$ per ml) were stimulated with HA-pulsed WT mice-derived BMDC $\left(2.5 \times 10^{5}\right.$ per ml $)$ in the presence of HA peptide $\left(1 \mu \mathrm{g} \mathrm{ml}^{-1}\right)$ and IL-2 $\left(200 \mathrm{ng} \mathrm{ml}^{-1}\right.$; eBioscience). When WT, $p f p^{-l-}$ or $I F N-\gamma^{-I}$ mice were used, 4T1, 4T1-HAc, 4T1-HA $\gamma$ RDN or 4T1-HA cells $\left(2 \times 10^{6}\right.$ cells $)$ were i.p. inoculated into the mice, then nylon nonadherent cells were prepared from splenic MNCs 7 days later and co-cultured with HA-pulsed WT mice-derived BMDC as described above. IFN- $\gamma\left(100 \mathrm{ng} \mathrm{ml}^{-1}\right.$; eBioscience) was supplemented into the culture for the in vitro stimulation of IFN- $\gamma^{-1-}$ mouse-derived nylon non-adherent cells. After 7 days of co-culture, cells were harvested and $\mathrm{CD} 8{ }^{+}$cells were purified by $\mathrm{CD} 8 \alpha^{+} \mathrm{T}$-cell isolation kit on autoMACS (Miltenyi Biotec) according to the manufacturer's instructions. Flow cytometric analysis demonstrated the $\mathrm{CD} 8{ }^{+}$cell population to be more than 95\% pure. To induce OVA-specific CTL, we used B6 WT mice for BMDC preparation, H-2K $\mathrm{K}^{\mathrm{b}}$-restricted OVS epitope peptide ( ${ }^{257}$ SIINFEKL ${ }^{264}$; Invitrogen) and OT1-mice for splenic MNCs preparation.

Preparation of tumour draining lymph node (DL) cells. Ten days after the inoculation of $4 \mathrm{~T} 1$ or $4 \mathrm{~T} 1$-HA cells $\left(2 \times 10^{5}\right.$ per foot $)$ into both footpads of BALB/c mice, $\mathrm{CD} 88^{+} \mathrm{T}$ cells were prepared from popliteal lymph node cells by $\mathrm{CD} 8 \alpha^{+}$T-cell isolation kit using autoMACS (Miltenyi Biotec) according to the manufacturer's instructions. Flow cytometric analysis demonstrated CD8 ${ }^{+}$cell population to be more than $95 \%$ pure.

\section{Adoptive cell transfer therapy (ACT). Prepared cells were transferred} intravenous (i.v.) into the mice $\left(5 \times 10^{6}-2 \times 10^{7}\right.$ cells per mice) on the same day as tumour inoculation, 7 and/or 14 days after tumour inoculation, or 5, 10, 14 and 18 days after tumour inoculation. In the experiments using EG7.1 cells, prepared OT-1 cells were transferred i.v. into the mice $\left(3 \times 10^{6}\right.$ cells per mice $)$ on the same day as tumour inoculation. In some experiments, WT mice-derived splenocytes were stimulated with Con A (Sigma; $5 \mathrm{\mu g} \mathrm{ml}^{-1}$ ) for 5 days in vitro, then whole cells or isolated $\mathrm{CD}_{8}{ }^{+}$cells were transferred into the mice on the same day as tumour inoculation. Some $R A G^{-1-}$ mice were treated with IL-12 (50 ng per mice; kindly provided by Genetics Institute, Andover, MA) or PBS every 2 days after tumour inoculation.

In the experiments using CMS5al cells (presented in Figs $4 c$ and $5 b$, Supplementary Fig. 9a,b; Fig. 6a,b), purified CD8 ${ }^{+} \mathrm{T}$ cells from spleen of DUC17 mice were transferred i.v. into the mice $\left(3 \times 10^{6}\right.$ cells per mice 2 days after tumour inoculation. Then, the mice were treated with $250 \mu \mathrm{g}$ of anti-mouse CD137 mAb $(3 \mathrm{H} 3)$, that was prepared and purified in our laboratory ${ }^{37}$, to activate T cells. In some experiments (presented in Figs $4 \mathrm{c}$ and $5 \mathrm{~b}$, Supplementary Fig. 9c,e,f; Fig. 7), WT mice were inoculated with CMS5al cells at footpads $\left(2 \times 10^{5}\right.$ per foot $)$ and treated with $250 \mu \mathrm{g}$ of anti-mouse $\mathrm{CD} 137 \mathrm{mAb}(3 \mathrm{H} 3)$ on day 0 and 5 , then $\mathrm{CD} 8^{+}$ T cells were prepared from DL 7 days after the tumour inoculation and used for ACT. In some experiments, some groups of $R A G^{-1-}$ mice were treated with ATR inhibitor VE822 (KareBay Biochem. Inc., Monmouth Junction, NJ; $60 \mathrm{mg} \mathrm{kg}^{-1}$ ) on day 5,7 and 9 (ref. 58). In the experiment using $4 \mathrm{~T} 1$-HAIFN $\gamma \mathrm{Tf}$, 4T1-HAIFN $\gamma$ Tf cells, $5 \times 10^{5}$ cells per mouse, were inoculated into $R A G^{-1-}$ mice. When palpable tumours developed after 10 days, mice were received DL cells $\left(5 \times 10^{7}\right.$ cell per mice) of WT or IFN- $\gamma^{-1-}$ mice that were inoculated with 4T1-HAIFN $\gamma$ Tf cells 7 days earlier. tumour cells were isolated from tumour mass 30 days after ACT.

ELISA for IFN- $\gamma$ produced by HA-specific or OVA-specific CTL. HA-specific CTL or CD8 ${ }^{+}$D.L. cells of tumour-bearing WT mice $\left(2.5 \times 10^{6}\right.$ cells per ml $)$ were co-cultured with $4 \mathrm{~T} 1$ or various $4 \mathrm{~T} 1$-derived cells $\left(1.25 \times 10^{6}\right.$ cells per ml $)$ for $16 \mathrm{~h}$ in $200 \mu \mathrm{l}$ of RPMI-1640 (Nissui Pharmaceutical, Tokyo, Japan) supplemented with $0.2 \mathrm{mM}$ L-glutamine (Wako), $25 \mathrm{mM} \mathrm{NaHCO}$ (Wako), $10 \%$ heat-inactivated fetal calf serum (FCS; JRH biosciences, Lenexa, KA), and $5 \times 10^{-5} \mathrm{M}$ 32-mercaptoethanol (Wako) on a 96-well flat-bottomed microtiter plate (Corning, Corning, NY) at $37^{\circ} \mathrm{C}$ in a $5 \%$ carbon dioxide humidified atmosphere. In the experiments using EG7.1 cells, OVA-specific OT-1 CTL cells were co-cultured with EG7.1 cells. Cell-free culture supernatants were collected, then IFN- $\gamma$ levels were evaluated by using a highly sensitive mouse IFN- $\gamma$ specific enzyme-linked immunosorbent assay (ELISA) kit (Ready-SET-Go!; eBioscience) according to the manufacturer's instructions.
Cytotoxicity assay. Cytotoxic activity against $4 \mathrm{~T} 1$ cells and various $4 \mathrm{~T} 1$ cell-derived clones was evaluated by a standard $4 \mathrm{~h}{ }^{51} \mathrm{Cr}$ release assay ${ }^{33,59}$. Some cells were pre-pulsed with HA peptide $\left(1 \mu \mathrm{g} \mathrm{ml}^{-1}\right)$ for $24 \mathrm{~h}$. Data are represented as the mean \pm s.d. of triplicate samples.

Western blotting. Tumour cells were freshly prepared as described above and lysed in RIPA buffer (1\% NP40, $50 \mathrm{mM}$ Tris- $\mathrm{HCl}$ (pH8.0), $150 \mathrm{mM} \mathrm{NaCl}, 0.5 \%$ deoxycollate and $10 \%$ SDS, $1 \mathrm{mM}$ sodium vanadate, $1 \mathrm{mM}$ sodium fluoride, $1 \mathrm{mM}$ phenylmethylsulfonyl fluoride, aprotinin $\left(1 \mu \mathrm{g} \mathrm{ml}^{-1}\right)$ and leupeptin $\left(1 \mu \mathrm{g} \mathrm{ml}^{-1}\right)$ ). After passing through a $26 \mathrm{G}$ needle followed by a $30 \mathrm{G}$ needle, total cell lysates were subjected to SDS-polyacrylamide gel electrophoresis (SDS-PAGE) and transferred onto polyvinylidene difluoride membranes (Miliipore). The membranes were analysed with anti-STAT1 mAb (1:1,000 dilution, \#9172, Cell Signaling Technology, Beverly, MA), anti-phospho STAT1 (Tyr701) mAb (1:1,000 dilution, \#7649, Cell Signaling Technology), anti-phospho STAT1 (Ser727) mAb (1:1,000 dilution, \#8826, Cell Signaling Technology), anti-STAT3 (1:1,000 dilution, \#9139, Cell Signaling Technology), anti-phospho STAT3 (Tyr705; 1:1,000 dilution, \#9145, Cell Signaling Technology) or anti- $\beta$-actin antibody (1:500 dilution, Poly6221, BioLegend). The membranes were developed with SuperSignal West Dura Extended Duration Substrate (Thermo Science) and analysed with an OptimaShot CL-420 $\alpha$ image analyzer (Wako, Osaka, Japan). All uncropped blots are shown in Supplementary Fig. 10.

Preparing for the side population and main population. 4T1-HA cells were suspended at $1 \times 10^{6}$ cells per $\mathrm{ml}$ in culture medium and stained with $9.0 \mu \mathrm{g} \mathrm{ml}^{-1}$ Hoechest 33342 (Sigma-Aldrich, St. Louis, MO) for $90 \mathrm{~min}$ at $37^{\circ} \mathrm{C}$ (ref. 60). After washing, cells were analysed and sorted by a triple laser MoFlo (Cytomation, Fort Collins, CO) with Summit software (Cytomation) at Keio GCOE FCM Core Facility (Keio University School of Medicine, Tokyo, Japan). Hoechst 33342 was excited at $350 \mathrm{~nm}$, and fluorescence emission was detected by using a 405/BP30 and 570/BP20 optical filter for Hoechst blue and Hoechst red, respectively, and a $550 \mathrm{~nm}$ long-pass dichroic mirror (all Omega Optical Inc.) to separate the emission wavelengths. Both Hoechst blue and red fluorescence are shown on a linear scale. Propidium iodide (PI) fluorescence was measured through 630BP30 after excitation at $488 \mathrm{~nm}$ with an argon laser, and a live cell gate was defined that excluded the cells positive for PI. Addition of $15 \mathrm{\mu g} \mathrm{ml}^{-1}$ reserpine resulted in the complete disappearance of the side population (SP) fraction (Sigma-Aldrich). Isolated SP and main population (MP) were re-suspended in culture medium and cell number and viability were confirmed. Then, cells were diluted to appropriate injection doses, mixed with BD Matrigel (BD Bioscience) according to manufacturer ${ }^{61}$

Array-based comparative genome hybridization analysis. Agilent SurePrint G3 Mouse Microarray $4 \times 180 \mathrm{~K}$ array technology (Agilent Technology, Inc., Palo Alto, USA) was used to analyse genomic structural variants ${ }^{62}$. Genomic DNA was isolated from tumour cells by chloroform/phenol extraction followed by ethanol precipitation (Sigma). Test and reference genomic DNAs (500 ng per sample) were fluorescently labelled with $\mathrm{Cy} 5$ (test samples) and $\mathrm{Cy} 3$ (reference: original cells that inoculated into the mice) with a Genomic DNA Enzymatic Labeling Kit (Agilent Technologies). All array hybridizations were performed according to the manufacturer's methods, immediately scanned with a G2565BA Microarray Scanner System (Agilent), and processed by Feature Extraction Software Ver. 10.7.3.1 (Agilent). All regions of statistically significant copy-number change were determined using Aberration Detection Method-2 (ADM2) algorithms on Agilent Genomic Workbench software version 6.5 Lite software (Agilent Technology) ${ }^{63}$. The ADM2 algorithms identify genomic regions with copy-number differences between the test and the reference based on $\log 2$ ratios of fluorescent signals from probes in the interval. Results were analysed under conditions that fuzzy zero was $\mathrm{ON}$ and Moving Average was set at $60 \mathrm{pt}$.

FISH analysis. Metaphase chromosome spreads were prepared from cultured mouse cells using conventional acetic acid-methanol fixation methods. Two bacterial artificial chromosomes (BACs) RP23-357M5 and RP23-146E14 were used to generate region-specific FISH probes for the amplified region (3A1) and for the reference region (3A3), respectively. BAC DNAs were labelled by nick-translation kit (Roche) according to the manufacturer's protocol with Cy5-dUTP (357M5) (Roche) and Green-dUTP (146E14; Abbott). To examine the transduced HA gene, MSCV-HA-IRES-GFP vector was labelled with Cy3-dUTP (Roche) and specific FISH probes for the centromere and telomere of chromosome 17 were labelled with Cy5-dUTP (Roche). The labelled probes were mixed with sonicated salmon sperm DNA and Cot-1 DNA in hybridization solution. The probes were applied to the pretreated sections, covered with coverslips and simultaneously denatured at $70^{\circ} \mathrm{C}$ for $5 \mathrm{~min}$. Hybridization was carried out at $37^{\circ} \mathrm{C}$ overnight. Slides were then washed with $50 \%$ formamide $/ 2 \times \mathrm{SSC}$ at $37^{\circ} \mathrm{C}$ for $20 \mathrm{~min}, 1 \times \mathrm{SSC}$ for $15 \mathrm{~min}$ at room temperature, counter-stained by 4,6-diamidino-2phenylindole (DAPI) and mounted. The FISH images were captured with the CW4000 FISH application program (Leica Microsystems Imaging Solution Ltd., Wetzlar, Germany) using a cooled CCD camera mounted on a Leica DMRA2 microscope. 
Quantitative RT-PCR. Total RNA was isolated from freshly prepared tumour cells using RNA STAT-60 (TEL-TEST Inc, Friendswood, TX) and first-stranded cDNA was prepared using oligo dT primers and TaqMan RT Reagents (Applied Biosystems, Foster City, CA). Quantitative PCR was performed following manufacturer's instructions ${ }^{35}$. Briefly, 7500 Real-Time PCR System (Applied Biosystems, Foster City, CA) was used with Assays-on Demand gene expression products (Applied Biosystems) of mouse target genes, Apobec1 (Mm01184109_m1), Apobec2 (Mm00477588_m1), Apobec3 (Mm01298575_m1), Apobec4 (Mm01287498_m1), Atm (Mm01177457_m1), Atr (Mm01223626_m1) or endogenous control GAPDH (Ma99999915 g1) and TaqMan Universal PCR Master Mix (Applied Biosystems). The expression levels of respective molecules were shown as a ratio compared with GAPDH in the same sample by calculation of cycle threshold $(\mathrm{Ct})$ value in amplification plots with 7500 SDS software (Applied Biosystems). Relative expression levels of respective molecules were calculated by relative quantification $(\Delta \Delta \mathrm{Ct})$ using SDS v1.2 with RQ software (Applied Biosystems) according to manufacturer's instructions. Results of all tested individual tumour cell and mean \pm s.d. are presented. For RT ${ }^{2}$ Profiler PCR Array for Mouse DNA repair (Qiagen, Venlo, Netherlands), cDNA was synthesized from $100 \mathrm{ng}$ of the total RNA using the RT ${ }^{2}$ preAMP cDNA synthesis kit (Qiagen), and the quality of isolated RNA was evaluated using RT $^{2}$ RNA QC PCR Arrays (Qiagen) according to the manufacturer's instructions. After all control tests, the samples were analysed using the RT ${ }^{2}$ Profiler PCR Array performed in 96-well plates on StepOnePlus (Applied Biosystems). The thresholds and baselines were set according to the manufacturer's instructions, and the data were analysed using software supplied on Qiagen homepage on website.

RT-PCR and genomic PCR. Total RNA was isolated as described above and first-stranded CDNA was prepared using oligo dT primers and TaqManRT Reagents (Applied Biosystems, Foster City, CA). Genomic DNA was prepared using Quiagen DNeay Blood \& Tissue Kit (Venlo, Netherlands). PCR reaction was performed ${ }^{64}$ using the following primers: HA33-1026: 5'-GACGGATCCATGAAGGCAAAC CTACTGGTC- $3^{\prime}$ and $5^{\prime}$-TGATTAACCATCCTCAATTTGGCAC- $3^{\prime}$; HA860-1733: $5^{\prime}$-GAAGAGGCTTTGGGGTCCGGCATCATCACC-3' and $5^{\prime}$-GACGCGGCCGCT CAGATGCATATTCTGCACTG-3'; OVA432-1125: $5^{\prime}$-GCTCATCAATTCCTG GGTAG- $3^{\prime}$ and $5^{\prime}$-GTTGGTTGCGATGTGCTTGA-3'; $\beta$-actin; $5^{\prime}$-TACGTAGC CATCCAGGCTGT- $3^{\prime}$ and $5^{\prime}$-AGGATGCGGCAGTGGCCAT- $3^{\prime}$.

To examine the expression of mERK, PCR reaction was performed using $5^{\prime}$-TTGGCATCAATGACAT- $3^{\prime}$ and $5^{\prime}$-TGTGGCTACGTACTCTGTC- ${ }^{\prime}$, then PCR products ( $320 \mathrm{bp}$ of wild-type ERK2 or mERK2 cDNA) were digested by $S f c l$ restriction enzyme (New England Biolabs, Beverly, MA) that selectively cleaves mERK, but not WT ERK2, to generate 159 and $161 \mathrm{bp}$ fragments ${ }^{29}$.

To confirm the genomic alteration of X chromosome of CMS5al demonstrated by a-CGH assay, quantitative genomic PCR was performed with Assays-on Demand gene expression products (Applied Biosystems) for a single exon of mouse target genes, Gm14374 (Mm03059176_gH) located on X Al.1,

Rnf113a1(Mm02343059_s1) located on X A3.3, or endogenous control $\beta$-actin (Mm00607939_m1) and TaqMan Universal PCR Master Mix (Applied Biosystems) as described above. Results of all tested individual tumour cell and mean \pm s.d. are presented.

\section{Histological examination for phospho-histone H2A.X. CMS5al and} CMS5al $\gamma$ RDN cells were inoculated in the left flank and the right flank, respectively, of the same $R A G^{-1-}$ mouse. Eighteen days after tumour inoculation, the mice were treated with $\mathrm{CD} 8{ }^{+}$DL cells of CMS5al-bearing WT mice treated with anti-CD137 mAb on the same day and 7 days after tumour inoculation. Tumour masses were harvested on day 20 ( 2 days after ACT) from ACT-treated mice and control ACT-non-treated mice, fixed in $10 \%$ formalin, and then embedded in paraffin. Following hematoxylin/eosin (HE) staining of paraffin sections ${ }^{65}$, to detect of phospho-Histone H2A.X (Ser139), paraffin sections were incubated with rabbit anti-phospho-Histone H2A.X (Ser139)( $\gamma$ H2A.X) mAb (clone 20E3) (Cell Signaling Technology, Denver, MA) and biotin-conjugated goat anti-rabbit IgG (Dako, Carpenteria, CA) in an automated immunostainer (BenchMark; Ventana Medical Systems, Tucson, AZ) by using an iVIEW DAB Detection Kit (Open Secondary; Ventana) and a Cell Conditioning Solution (CC1; Ventana). Finally, sections were counter-stained with hematoxylin, and were scanned in a Virtual Slide System (VS110; Olympus, Tokyo, Japan). The whole area of tumour margin was examined in each specimen, and the numbers of positively nucleus, $\%$ of intact area and \% of cell death area were calculated by image analysis software, Tissue Studio v.2.3 (Definiens AG, Munich, Germany).

Statistical analysis. Statistical analysis was performed by unpaired, two-tailed Student's $t$-test for the cytotoxicity and quantitative PCR analysis. $P$ values $<0.05$ were considered as significant.

Data availability. The array CGH data have been deposited in the NCBI database under the accession code GSE92271. The authors declare that all the other data supporting the findings of this study are available within the article and its Supplementary Information files and from the corresponding author upon reasonable request.

\section{References}

1. Schreiber, R. D., Old, L. J. \& Smyth, M. J. Cancer immunoediting: integrating immunity's roles in cancer suppression and promotion. Science 331, 1565-1570 (2011).

2. Hanahan, D. \& Weinberg, R. A. Hallmarks of cancer: the next generation. Cell 144, 646-674 (2011).

3. Matsushita, H. et al. Cancer exome analysis reveals a T-cell-dependent mechanism of cancer immunoediting. Nature 482, 400-404 (2012).

4. DuPage, M., Mazumdar, C., Schmidt, L. M., Cheung, A. F. \& Jacks, T. Expression of tumour-specific antigens underlies cancer immunoediting. Nature 482, 405-409 (2012).

5. Shankaran, V. et al. IFN $\gamma$ and lymphocytes prevent primary tumour development and shape tumour immunogenicity. Nature 410, 1107-1111 (2001).

6. Braumüller, H. et al. T-helper-1-cell cytokines drive cancer into senescence. Nature 494, 361-365 (2013).

7. Zaretsky, J. M. et al. Mutations associated with acquired resistance to PD-1 blockade in melanoma. N. Engl. J. Med. 375, 819-829 (2016).

8. Textor, A. et al. Preventing tumor escape by targeting a post-proteasomal trimming independent epitope. J. Exp. Med. 213, 2333-2348 (2016).

9. Helmich, B. K. \& Dutton, R. W. The role of adoptively transferred CD8 T cells and host cells in the control of the growth of the EG7 thymoma: factors that determine the relative effectiveness and homing properties of Tc1 and Tc2 effectors. J. Immunol. 166, 6500-6508 (2001).

10. Tanaka, N. et al. Cooperation of the tumour suppressors IRF-1 and p53 in response to DNA damage. Nature 382, 816-818 (1996).

11. Dighe, A. S., Richards, E., Old, L. J. \& Schreiber, R. D. Enhanced in vivo growth and resistance to rejection of tumor cells expressing dominant negative IFN $\gamma$ receptors. Immunity 1, 447-456 (1994).

12. Hanada, T. et al. IFN $\gamma$-dependent, spontaneous development of colorectal carcinomas in SOCS1-deficient mice. J. Exp. Med. 203, 1391-1397 (2006).

13. Zaidi, M. R. et al. Interferon- $\gamma$ links ultraviolet radiation to melanomagenesis in mice. Nature 469, 548-553 (2011).

14. Taube, J. M. et al. Colocalization of inflammatory response with B7-h1 expression in human melanocytic lesions supports an adaptive resistance mechanism of immune escape. Sci. Transl. Med. 4, 127ra137 (2012).

15. Schürch, C., Riether, C., Amrein, M. A. \& Ochsenbein, A. F. Cytotoxic T cells induce proliferation of chronic myeloid leukemia stem cells by secreting interferon- $\gamma$. J. Exp. Med. 210, 605-621 (2013).

16. Katsurano, M. et al. Early-stage formation of an epigenetic field defect in a mouse colitis model, and non-essential roles of T- and B-cells in DNA methylation induction. Oncogene 31, 342-351 (2012).

17. Dunn, G. P., Koebel, C. M. \& Schreiber, R. D. Interferons, immunity and cancer immunoediting. Nat. Rev. Immunol. 6, 836-848 (2006).

18. Zaidi, M. R. \& Merlino, G. The two faces of interferon- $\gamma$ in cancer. Clin. Cancer Res. 17, 6118-6124 (2011).

19. Zou, Q. et al. T cell intrinsic USP15 deficiency promotes excessive IFN- $\gamma$ production and an immunosuppressive tumor microenvironment in MCAinduced fibrosarcoma. Cell Rep. 13, 2470-2479 (2015).

20. Zack, T. I. et al. Pan-cancer patterns of somatic copy number alteration. Nat. Genet. 45, 1134-1140 (2013).

21. Pinkel, D. \& Albertson, D. G. Array comparative genomic hybridization and its applications in cancer. Nat. Genet. 37(Suppl): S11-S17 (2005).

22. Maser, R. S. et al. Chromosomally unstable mouse tumours have genomic alterations similar to diverse human cancers. Nature 447, 966-971 (2007).

23. Westcott, P. M. et al. The mutational landscapes of genetic and chemical models of Kras-driven lung cancer. Nature 517, 489-492 (2015).

24. McFadden, D. G. et al. Genetic and clonal dissection of murine small cell lung carcinoma progression by genome sequencing. Cell 156, 1298-1311 (2014).

25. Gao, R. et al. Punctuated copy number evolution and clonal stasis in triple-negative breast cancer. Nat. Genet. 48, 1119-1130 (2016).

26. Notta, F. et al. A renewed model of pancreatic cancer evolution based on genomic rearrangement patterns. Nature 538, 378-382 (2016).

27. Markowetz, F. A saltationist theory of cancer evolution. Nat. Genet. 48, 1102-1103 (2016).

28. Kottke, T. et al. Detecting and targeting tumor relapse by its resistance to innate effectors at early recurrence. Nat. Med. 19, 1625-1631 (2013).

29. Matsui, K., O’Mara, L. A. \& Allen, P. M. Successful elimination of large established tumors and avoidance of antigen-loss variants by aggressive adoptive T cell immunotherapy. Int. Immunol. 15, 797-805 (2003).

30. Swanton, C., McGranahan, N., Starrett, G. J. \& Harris, R. S. APOBEC enzymes: mutagenic fuel for cancer evolution and heterogeneity. Cancer Discov. 5, 704-712 (2015).

31. Mehta, H. V., Jones, P. H., Weiss, J. P. \& Okeoma, C. M. IFN- $\alpha$ and lipopolysaccharide upregulate APOBEC3 mRNA through different signaling pathways. J. Immunol. 189, 4088-4103 (2012).

32. Chiu, Y. T. et al. Inactivation of ATM/ATR DNA damage checkpoint promotes androgen induced chromosomal instability in prostate epithelial cells. PLoS ONE 7, e51108 (2012). 
33. Uno, T. et al. Eradication of established tumors in mice by a combination antibody-based therapy. Nat. Med. 12, 693-698 (2006).

34. Smyth, M. J. et al. Tumor necrosis factor-related apoptosis-inducing ligand (TRAIL) contributes to interferon $\gamma$-dependent natural killer cell protection from tumor metastasis. J. Exp. Med. 193, 661-670 (2001).

35. Takeda, K. et al. IFN- $\gamma$ production by lung NK cells is critical for the natural resistance to pulmonary metastasis of B16 melanoma in mice. J. Leukoc. Biol. 90, 777-785 (2011).

36. Benci, J. L. et al. Tumor interferon signaling regulates a multigenic resistance program to immune checkpoint blockade. Cell 167, 1540-1554 (2016).

37. Magnus, N. et al. Tissue factor expression provokes escape from tumor dormancy and leads to genomic alterations. Proc. Natl Acad. Sci. USA 111, 3544-3549 (2014)

38. Hölzel, M., Bovier, A. \& Tuting, T. Plasticity of tumour and immune cells: a source of heterogeneity and a cause for therapy resistance? Nat. Rev. Cancer 13, 365-376 (2013).

39. Wang, Y. et al. Clonal evolution in breast cancer revealed by single nucleus genome sequencing. Nature 512, 155-160 (2014).

40. Landsberg, J. et al. Melanomas resist T-cell therapy through inflammationinduced reversible dedifferentiation. Nature 490, 412-416 (2012).

41. Restifo, N. P., Dudley, M. E. \& Rosenberg, S. A. Adoptive immunotherapy for cancer: harnessing the T cell response. Nat. Rev. Immunol. 12, 269-281 (2012).

42. Khong, H. T. \& Restifo, N. P. Natural selection of tumor variants in the generation of 'tumor escape' phenotypes. Nat. Immunol. 3, 999-1005 (2002).

43. Willimsky, G. \& Blankenstein, T. Sporadic immunogenic tumours avoid destruction by inducing T-cell tolerance. Nature 437, 141-146 (2005).

44. Rooney, M. S., Shukla, S. A., Wu, C. J., Getz, G. \& Hacohen, N. Molecular and genetic properties of tumors associated with local immune cytolytic activity. Cell 160, 48-61 (2015).

45. Champiat, S., Ferte, C., Lebel-Binay, S., Eggermont, A. \& Soria, J. C. Exomics and immunogenics: bridging mutational load and immune checkpoints efficacy. Oncoimmunology 3, e27817 (2014).

46. Engels, B. et al. Relapse or eradication of cancer is predicted by peptide-major histocompatibility complex affinity. Cancer Cell 23, 516-526 (2013).

47. Leisegang, M. et al. Eradication of large solid tumors by gene therapy with a $\mathrm{T}$ cell receptor targeting a single cancer-specific point mutation. Clin. Cancer Res. 22, 2734-2743 (2015).

48. Lollini, P. L., Cavallo, F., Nanni, P. \& Forni, G. Vaccines for tumour prevention. Nat. Rev. Cancer 6, 204-216 (2006).

49. Cretney, E. et al. Increased susceptibility to tumor initiation and metastasis in TNF-related apoptosis-inducing ligand-deficient mice. J. Immunol. 168, 1356-1361 (2002).

50. Kodama, T. et al. Perforin-dependent NK cell cytotoxicity is sufficient for anti-metastatic effect of IL-12. Eur J. Immunol. 29, 1390-1396 (1999).

51. Berner, V. et al. IFN- $\gamma$ mediates CD4 ${ }^{+}$T-cell loss and impairs secondary antitumor responses after successful initial immunotherapy. Nat. Med. 13, 354-360 (2007).

52. Marzo, A. L. et al. Tumor antigens are constitutively presented in the draining lymph nodes. J. Immunol. 162, 5838-5845 (1999).

53. Coughlin, C. M. et al. Tumor cell responses to IFN $\gamma$ affect tumorigenicity and response to IL-12 therapy and antiangiogenesis. Immunity 9, 25-34 (1998).

54. Nakajima, K. et al. A central role for Stat3 in IL-6-induced regulation of growth and differentiation in M1 leukemia cells. EMBO J. 15, 3651-3658 (1996).

55. Takeda, K., Hatakeyama, K., Tsuchiya, Y., Rikiishi, H. \& Kumagai, K. A correlation between GM-CSF gene expression and metastases in murine tumors. Int. J. Cancer 47, 413-420 (1991).

56. Norbury, C. C., Chambers, B. J., Prescott, A. R., Ljunggren, H. G. \& Watts, C. Constitutive macropinocytosis allows TAP-dependent major histocompatibility complex class I presentation of exogenous soluble antigen by bone marrowderived dendritic cells. Eur. J. Immunol. 27, 280-288 (1997).

57. Hayakawa, Y. et al. NK cell TRAIL eliminates immature dendritic cells in vivo and limits dendritic cell vaccination efficacy. J. Immunol. 172, 123-129 (2004).
58. Fokas, E. et al. Targeting ATR in vivo using the novel inhibitor VE-822 results in selective sensitization of pancreatic tumors to radiation. Cell Death Dis. 3, e441 (2012).

59. Takeda, K. et al. Critical role for tumor necrosis factor-related apoptosisinducing ligand in immune surveillance against tumor development. J. Exp. Med. 195, 161-169 (2002)

60. Masuda, H. et al. Stem cell-like properties of the endometrial side population: implication in endometrial regeneration. PLoS ONE 5, e10387 (2010).

61. Dalerba, P. et al. Phenotypic characterization of human colorectal cancer stem cells. Proc. Natl Acad. Sci. USA 104, 10158-10163 (2007).

62. Trask, B. J. Fluorescence in situ hybridization: applications in cytogenetics and gene mapping. Trends Genet. 7, 149-154 (1991).

63. Lipson, D., Aumann, Y., Ben-Dor, A., Linial, N. \& Yakhini, Z. Efficient calculation of interval scores for DNA copy number data analysis. J. Comput. Biol. 13, 215-228 (2006).

64. Kawamura, T. et al. Critical role of $\mathrm{NK} 1{ }^{+} \mathrm{T}$ cells in IL-12-induced immune responses in vivo. J. Immunol. 160, 16-19 (1998).

65. Takeda, K. et al. Induction of tumor-specific T cell immunity by anti-DR5 antibody therapy. J. Exp. Med. 199, 437-448 (2004).

\section{Acknowledgements}

We are grateful to DNA Chip Research Inc. (Yokohama, Japan) and Chromosome Science Labo Inc. (Sapporo, Japan) for their technical support. We thank Dr Yumi Matsuzaki and Dr Suzuki Sadafumi (Department of Physiology and Keio GCOE FCM Core Facility, Keio University School of Medicine, Tokyo, Japan) for their technical support and Dr Johji Inazawa (Department of Molecular Cytogenetics, Tokyo Medical and Dental University, Tokyo, Japan) and Dr Nick Hayward (QIMR Berghofer) for helpful discussion. This work was supported by the Ministry of Education, Science, and Culture, Japan. M.J. Smyth was supported by a National Health and Medical Research Council of Australia Research Fellowship, and an Association for International Cancer Research (UK) Project Grant.

\section{Author contributions}

K.T. designed the project, performed the experiments, interpreted the data and wrote the manuscript. M.N. and Y.K. performed experiments and wrote the manuscript. H.I. and N.I. provided the key materials. Y.H., K.Og. and K.Ok. revised the manuscript. D.M.T and M.J.S. interpreted the data, provided resources and wrote the manuscript.

\section{Additional information}

Supplementary Information accompanies this paper at http://www.nature.com/ naturecommunications

Competing financial interests: The authors declare no competing financial interests.

Reprints and permission information is available online at http://npg.nature.com/ reprintsandpermissions/

How to cite this article: Takeda, K. et al. IFN- $\gamma$ is required for cytotoxic $\mathrm{T}$ cell-dependent cancer genome immunoediting. Nat. Commun. 8, 14607 doi: $10.1038 /$ ncomms14607 (2017).

Publisher's note: Springer Nature remains neutral with regard to jurisdictional claims in published maps and institutional affiliations.

(c) (i) This work is licensed under a Creative Commons Attribution 4.0 BY International License. The images or other third party material in this article are included in the article's Creative Commons license, unless indicated otherwise in the credit line; if the material is not included under the Creative Commons license, users will need to obtain permission from the license holder to reproduce the material. To view a copy of this license, visit http://creativecommons.org/licenses/by/4.0/

C) The Author(s) 2017 